\title{
El destructor de huacas. La acción de Manuel B. Zavaleta en la constitución del "patrimonio arqueológico" calchaquí y el respaldo del Estado argentino, fines del siglo XIX y principios del XX
}

\section{The destroyer of huacas. The action of Manuel B. Zavaleta in the constitution of the "archaeological heritage" and the support of the Argentine state, late nineteenth and early twentieth centuries}

\author{
Sandra Tolosa ${ }^{1}$ https://orcid.org/0000-0002-8746-6393 \\ ${ }^{1}$ Instituto de Ciencias Antropológicas, Facultad de Filosofía y Letras, Universidad \\ de Buenos Aires, Buenos Aires, ARGENTINA. Email: cahsandra@gmail.com
}

\begin{abstract}
Resumen
En este trabajo reviso la actividad comercial de Manuel Zavaleta con materiales arqueológicos de los valles calchaquíes en el cambio de siglo XIX-XX, haciendo foco en sus ventas de colecciones al Estado nacional argentino. Partiendo de la perspectiva de que los procesos de patrimonialización deben ser observados como producto de la interacción concreta entre actores y agencias, este recorrido problematiza la trayectoria de este "enemigo" de la arqueología científica - por sus efectos destructivos y ausencia de métodos de excavación y registro-. Estos aspectos negativos, sumamente importantes para la práctica disciplinar y para la perspectiva patrimonial, han opacado otros factores que posibilitaron su accionar, como la demanda de piezas para la formación de colecciones en las instituciones metropolitanas y, especialmente, la responsabilidad del poder político estatal en ese proceso.
\end{abstract}

Palabras claves: comercio de antigüedades, formación de colecciones, patrimonialización.

\begin{abstract}
In this paper I review the commercial activity of Manuel Zavaleta with archaelogical materials from the Calchaquí valleys at the turn of the XIX-XX century, focusing on his sales of collections to the Argentine national state. Starting from the perspective that patrimonialization processes must be observed as a product of the concrete interaction between actors and agencies, this journey problematizes the trajectory of this «enemy» of scientific archeology - due to its destructive effects and the absence of excavation methods and registry-. These negative aspects, extremely important for the disciplinary practice and for the patrimonial perspective, have forgotten other factors that made their action possible, as the demand for pieces for the formation of collections in metropolitan institutions and especially the responsibility of the state political power in that process.
\end{abstract}

Keywords: antiques trade, collection training, indigenous heritage, patrimonialization.

Recibido: 6 diciembre 2018. Aceptado: 27 abril 2019 


\section{Introducción}

En el cambio de siglo del XIX al XX, en un contexto internacional de crecimiento y consolidación de los museos, la compulsión acumulativa de materiales arqueológicos y antropológicos -entre otrosdestinados a formar colecciones fue replicada en las instituciones más importantes de Argentina, como el Museo Nacional (antes Museo Público, fundado en 1825 por Bernardino Rivadavia), el Museo de La Plata, fundado en 1884 por Francisco Moreno y el Museo Etnográfico, fundado en 1904 por Juan B. Ambrosetti, estudiados por diversos autores (Podgorny, 1995; Lopes, 2000; Farro, 2008; Podgorny y Lopes, 2008; Pegoraro, 2009; Perazzi, 2011, entre otros).

Durante esta etapa se utilizaron distintas estrategias para conseguir materiales destinados a la exhibición y el estudio como donaciones, canjes, excavaciones de los propios científicos y compra de objetos a coleccionistas y en el campo. Esto último constituía un objetivo de las expediciones, al que se destinaba una cantidad del dinero presupuestado. Esta combinación de prácticas conformó la base de las colecciones en un proceso de acumulación poco regulado, dependiente en parte de las personalidades a cargo de las instituciones y con un apoyo financiero estatal poco sistemático, ya que si bien se erogaban recursos -por ejemplo para adquirir colecciones-, poco se invertía en sostener la infraestructura edilicia de los museos o en sus investigaciones.

Esto debe comprenderse, sin embargo, en un contexto en donde aún no existía un proyecto consolidado sobre el patrimonio estatal ni sobre el conocimiento como bien público, en tanto, como he planteado (Tolosa, 2018), el rol del Estado argentino respecto de estos puntos en el último cuarto del siglo XIX debe enmarcarse como parte del proceso de un Estado en "formación", que avanzaba en la centralización del poder y de sus facultades. Respecto del "patrimonio", recién durante la presidencia de Julio A. Roca comenzó a plantearse la asociación entre la posesión de los recursos culturales y el paradigma hegemónico del Estado soberano con la nacionalización conjunta del Museo, Archivo y Biblioteca Públicos de Buenos Aires, acto que manifestó el poder del Estado de expropiar "documentos y objetos históricos que existiesen en la Provincia que por su naturaleza correspondían a la Nación" (MJCIP 1885: CXXXVIII). Sobre el Museo en particular, se especificaba: "guarda un crecido número de objetos que perpetúan la memoria de hechos, cosas y personas jenuinamente nacionales, lo mismo que diversas colecciones científicas reunidas en todo el territorio de la República, debiendo y conviniendo, por lo tanto, ser nacionalizado y conservarse en esta ciudad." (MJCIP, 1885, p. 1142). Este proceso tendría su corolario recién en 1913 con la sanción de la Ley Nacional 9080, que puso fin a la etapa de acumulación, planteó la patrimonialización estatal de materiales y sitios y designó los agentes autorizados para su manipulación.

En particular, la aparición en escena de "lo calchaquí" a fines de la década de 1870 produjo gran interés y se consolidó rápidamente como objeto de estudio privilegiado. Estas piezas provenían de los valles interserranos que atraviesan las actuales provincias de Catamarca, Tucumán y Salta, donde se asentaban numerosos grupos indígenas que enfrentaron el avance espańol durante más de 130 ańos; pero pese a su diversidad, fueron clasificados en forma genérica como "calchaquíes" por los antropólogos y arqueólogos de fines del siglo XIX. Las primeras referencias aparecieron en la prensa salteña y fueron recogidas por los Anales de la Sociedad Cientifica Argentina (Leguizamón, 1876a y b; Pringles, 1876a y b); los primeros objetos de los valles calchaquíes y "de los túmulos del país de los indios Quilmes" (SCA, 1876 II, p. 35) se expusieron en Buenos Aires en la Segunda Exposición Anual de la Sociedad. Algunos fueron remesados por Leguizamón (1876c), otros pertenecían a Moreno y dos a Nolasco Ortiz Viola (SCA, 1876 III, pp. 140-141 y 146-147). En 1877 llegó a Buenos Aires el Álbum de la expedición a la Loma Rica de los profesores del Colegio Nacional de Tucumán Inocencio Liberani y Rafael Hernández, realizada con aval del Ministerio de Justicia, Culto e Instrucción Pública de la Nación (MJCIP). Este álbum, junto a otro de Moreno representando al Museo de La Plata y los objetos de Leguizamón, fue catalogado en la Sección Antropológica Argentina en la Exposición Universal de París de 1878 (Ameghino, 1878) adquiriendo un alcance internacional. 
Las producciones calchaquíes mostraban la existencia de poblaciones prehispánicas "complejas" por su grado de urbanización, tecnología y sedentarización, que contrastaban con las crónicas españolas que lo describían como feroz e incivilizado, dando lugar a controversias sobre la antigüedad y origen de esa población (Giudicelli, 2011). Al mismo tiempo, la magnitud y complejidad de sus ciudades, así como la cantidad y "calidad" artística de sus producciones, constituyeron un material atrayente, lo que motivó una intensa labor extractiva que no siempre redundó en una ampliación del conocimiento, ya que si bien interesaba el valor estético, "no hubo ningún interés en estudiarlos en sus precisas asociaciones al interior de los lugares funerarios y asentamientos de los que habían sido extraídos" (Tarragó, 2003, p. 21).

Entre las distintas consecuencias que trajo el interés por estas piezas, este trabajo se inserta en una en particular: el nacimiento de un mercado de antigüedades que respondió a la demanda de los coleccionistas y que a su vez ocasionó un cambio en la percepción de los pobladores locales sobre los objetos de los "Antiguos" - devenidos en recursos económicos- que dio lugar a lo que hasta hoy denominamos "huaqueo", ${ }^{1}$ término utilizado en el Cono Sur desde el siglo XX para referirse a la actividad del "excavador profesional de yacimientos arqueológicos precolombinos" (Academia Argentina de Letras, 1942, p. 870). La búsqueda de piezas para la venta tuvo en la zona distintos alcances de acuerdo a la posición social de los sujetos que la realizaban; mientras algunos vendían piezas sueltas o en escasa cantidad, otros de mayores recursos formaban colecciones considerables (Tolosa, 2018).

1 El término, derivado del quechua, combina el concepto andino de waca (o huaca) como espacio sagrado con la práctica de excavación, con distintos objetivos a lo largo del tiempo. Durante la Colonia, la búsqueda se orientaba a los "tapados" o tesoros, ocultos por los indígenas antes de ser vencidos; posteriormente, se sumaron leyendas sobre ocultamientos por parte de los mismos españoles, cuyos "derroteros" se vendían engañosamente a los comerciantes de mulas que viajaban desde la zona calchaquí a Bolivia y a Perú. A fines del XIX, la búsqueda se reorientó a la extracción de piezas arqueológicas y restos humanos para su venta a instituciones y coleccionistas.
Entre ellos, el más importante de la zona calchaquí fue Manuel Benjamín Zavaleta, quien desplegó en el cambio de siglo una actividad comercial de piezas arqueológicas sin precedentes, tanto en el país como en el extranjero, que ha llevado a que se le considere como una figura paradigmática del "huaqueo" en Argentina, cuyos efectos negativos sobre sitios y materiales arqueológicos y la pérdida patrimonial ocasionada por sus ventas al extranjero fueron denunciados desde sus contemporáneos hasta la actualidad (Lafone Quevedo, 1897; De La Vaulx, 1901; Ambrosetti, 1907; González, 1983; Scattolin, 2003; Tarragó, 2003, entre otros).

Menos son los autores que hacen referencia a las condiciones históricas en las que se insertó la actividad de Zavaleta. Farro (2008) ha analizado su vinculación con el campo científico a partir del Museo de La Plata; Gluzman (2018) señala su capacidad de vinculación con diferentes actores e instituciones para el logro de sus objetivos. Respecto del Estado en particular, Lenton (2005) ha relacionado las compras a Zavaleta con el inicio de una "nueva "preocupación” política por lo que comienza a definirse como riqueza cultural "en peligro", es decir que "las reliquias de una Argentina "diferente" (indígena) pudiesen irse al extranjero” (Lenton, 2005, p. 181).

En este trabajo analizaré la actividad de Zavaleta, haciendo foco en sus ventas de colecciones al Estado argentino, partiendo de la premisa de que el contexto y las condiciones de época no pueden ser pensados solo como instrumentos utilizados por Zavaleta para desarrollar su negocio, sino que es necesario revisar las responsabilidades de las otras agencias y actores involucrados y copartícipes en este proceso general de expoliación, comercialización y patrimonialización estatal de decenas de miles de piezas de origen indígena, como fueron las instituciones científicas y el poder político del Estado.

En este caso, me enfocaré en la responsabilidad y participación del Estado argentino en la compra de colecciones destinadas a la formación de su propio patrimonio, que no solo permitió sino que impulsó la carrera comercial de Zavaleta. Sin embargo, es necesario señalar que el rol fundamental del Estado no se debió a que este solicitara comprar las colecciones, como indica Gluzman (2018, p. 78). 
Los documentos de archivo indican que siempre fue Zavaleta quien ofreció sus colecciones al Estado y promovió las transacciones a partir de sus contactos interpersonales y no a la inversa.

Para comprender la articulación entre Zavaleta y el poder político, revisaré primero algunas características de su posición social, planteando que su pertenencia de clase y sus vinculaciones fueron la plataforma que le posibilitó desarrollar su actividad. Posteriormente, realizaré una revisión de las ventas de colecciones, haciendo foco en aquellas adquiridas por el Estado argentino y en su activa participación en la conformación de los valores y precios de las colecciones. Entretanto, iré analizando la construcción de una "estrategia" discursiva y relacional que le permitió a Zavaleta multiplicar sus vínculos con el fin de realizar sus negocios.

\section{El misterioso señor Zavaleta}

Un aspecto curioso de este personaje es que a pesar de su "fama" como uno de los mayores destructores del patrimonio arqueológico de la zona calchaquí, los datos de su biografía son casi inexistentes, lo que complejiza la tarea de reconstruir su figura y trayectoria, solo rastreable a partir de datos discontinuos. La información de este apartado fue reconstruida desde el cruce de datos de archivo, genealógicos, catastrales, de hemeroteca y de lo aportado por una descendiente. Las lagunas que quedan podrán ser completadas en la medida que surja nueva información.

Un problema que ha traído confusiones, es que la familia Zavaleta comprende varias ramas a partir de un tronco común, constituyendo una red en la que se repiten nombres y entrelazan apellidos, lo que crea múltiples confusiones. La reconstrucción realizada me permite indicar que la familia Zavaleta pertenecía a una segunda línea de la élite tucumana (Herrera, 2006), ${ }^{2}$ cimentada en su poder económico y político, y en la proliferación de lazos familiares y alianzas matrimoniales endogámicas, que la curia

2 Luego de las familias Frías, Nougués, Posse, Padilla y Avellaneda, pero en estrecha relación, estaban los Etchecopar, Helguera, Molina, Gallo, Cossio, Paz, Cainzo, Méndez, Silva, Zavaleta y Zavalía, entre otras. dispensaba en cada boda para perpetuar el círculo de la oligarquía tucumana.

Manuel Benjamín Zavaleta de la Vega fue bautizado el 5 de marzo de 1862 en Tucumán, parte de la cuarta generación descendiente del matrimonio de Dolores Ruiz Huidobro Aráoz (1773-1806) y José Clemente de Zavaleta Indá (1762-1830), gobernador de Tucumán, que tuvo siete hijos. De ellos, Francisco de Paula Benito Zavaleta y Ruiz de Huidobro (1805-1851) tuvo tres hijos con Manuela Vázquez de Talavera: Ángela, Julio y Benjamín Zavaleta Vázquez. Este último, junto a Dalmira de la Vega Silva, fue padre de Manuel Benjamín y sus hermanos.

De las ramificaciones de los otros hijos de Zavaleta Indá y Ruiz Huidobro surgieron actores importantes del escenario político y económico provincial y nacional del siglo XIX, o se casaron con protagonistas. Por ejemplo, Juana Tomasa se casó con José Manuel Silva Helguera, gobernador de Tucumán entre 1828-29; su hija Dolores Silva Zavaleta lo hizo con Marco Manuel de Avellaneda, gobernador de Tucumán, cuyo hijo Nicolás fue presidente de la nación. Su otra hija, Juana Tomasa Silva, se casó con su tío Lucas Zavaleta; sus hijos Clemente y Lucas serían dueños de la mayor parte de Tafí. Al mismo tiempo, Juana era abuela de Dalmira y tía de su esposo Benjamín, por lo tanto bisabuela y tía abuela (al mismo tiempo) del huaquero. Este pequeño recorte da cuenta de los complejos y endogámicos tejidos parentales en los cuales la familia se insertaba.

Un dato repetido por diferentes autores (que provendría de Adán Quiroga) indica que Zavaleta era comisario de Fuerte Quemado, Catamarca, adjudicando sobre esto un "ejercicio inescrupuloso del cargo" (Gluszman, 2018) que le permitía acceder a los campos y controlar la mano de obra local. Otras versiones indican que era hacendado, versión sostenida por él mismo cuando en sus hiperbólicos relatos se decía heredero de "one of the most extensive ranches in the Argentine." "Scars on Skulls interest scientist”, 1904). Una descendiente señala que poseía una casa de comercio en San Miguel. También se lo ha descripto como un "veraneante de Tafí del Valle" a quien sus ricos parientes le permitían excavar sus tierras, facilitándole peones (Peña de Baskary, 1975, p. 6). Estos parientes eran la rama Zavaleta 
Silva, grandes propietarios ${ }^{3}$ que se asentaron tempranamente en Tafí; Lucas M. Zavaleta compró la estancia Infiernillo o Río Blanco; El Churqui, por su parte, fue heredada por Clemente Zavaleta y Josefa Rueda a sus descendientes Clemente y Lucas M. Zavaleta (Rivas, 2000), primos hermanos del padre de Manuel, Benjamín Zavaleta Vásquez. Este fue diputado provincial en 1866 (Herrera, 2006) y uno de los pocos que acompańó al presidente Nicolás Avellaneda en su último viaje a Tucumán en 1884, cuando su salud ya estaba deteriorada (Páez de la Torre, 2013). Su esposa Dalmira -copropietaria por herencia de una franja de tierras en Cebil Redondo, Tafí- era hija de Agustín de la Vega (diputado provincial, senador nacional y ministro de la Confederación) y de Tomasa Silva Zavaleta (hermana de Dolores y de Juana). Es decir, la madre de Manuel era prima hermana del presidente y de su hermano Marco, diputado, senador y ministro.

En mayo de 1889 Manuel Zavaleta, con 27 años, se casó con Margarita Esteves Zavalía, de 16 años de edad (1871-1903), en la Iglesia Matriz de Tucumán. Uno de sus testigos fue Lautaro Posse, hijo de Wenceslao, figura central de la política y economía tucumanas. Los contrayentes eran parientes consanguíneos en cuarto grado, impedimento que fue dispensado por la curia, como era costumbre. Los Esteves eran importantes propietarios: la estancia Las Tacanas fue heredada por la suegra de Manuel, Margarita Zavalía Esteves. Debido a un remate, su hijo compró la finca con la dote de su esposa, quedando en manos de la familia. Allí se criaron los cinco hijos de Manuel, la última nacida en $1902 .{ }^{4}$

3 Las estancias de Tafí, surgidas del fraccionamiento de tierras jesuitas en potreros, a fines del siglo XIX eran propiedad de pocas familias que concentraban 16000 ha. La Banda y Las Carreras pertenecían a Justiniano, Adelina Frías y Dolores Silva (familia del gobernador José Frías Silva y propietarios de los ingenios San José y Santa Lucía); El Mollar fue heredado por Clementina Silva y Justiniano Frías; Los Cuartos y La Angostura, por la familia Chenaut.

4 Los hijos del matrimonio fueron Raquel María (18901973), María Esther (1892-1980), Sara María (18941987), Laura María (s.d.) y Manuel Benjamín María (1899-1938), según información recuperada de www. genealogía.net y www.familysearch.org.ar
$\mathrm{Al}$ año siguiente muere Margaritilla (así se la recuerda) Esteves. El viudo vendió su casa de comercio «La Vallista» que tenía en Tucumán y se dedicó a viajar. En 1904 se encontraba en París, en 1909 en Polonia. En 1914 muere mi bisabuela Margarita Zavalía quien se hizo cargo de sus cinco nietos huérfanos. Zavaleta se volvió a casar y no volvió nunca más a Tucumán (sobrina nieta de Zavaleta, com. pers., agosto 2013).

Estos datos indican que, al menos cuando comenzó con su actividad arqueológica, las tierras no eran posesión personal de Manuel, sino de sus familias de sangre y política.

No ha sido posible por el momento encontrar datos que permitan asegurar si tuvo formación escolar o profesional. Pero sí es evidente que Manuel tenía un carácter emprendedor. Además del comercio mencionado por su familiar (del cual no encontré más datos) en la década de 1880 fundó El Gliptodonte, la primera fábrica de hielo de Tucumán y ejemplo de su espíritu innovador: hasta allí el hielo compacto se cortaba con hacha y, envuelto en paja, se trasladaba en chihuas (cilindros de madera) a lomo de mula a la ciudad, desde la cima del Aconquija o de explotaciones de menor altura como Cerro de Piedras Negras o Chaquivil, donde había manantiales de roca (Groussac et al., 1882, p. 281). La fábrica sería vendida ańos después con una hipoteca ("Bottini Ángel compra fábrica e hipoteca a Zavaleta Manuel B.”, 1895). Mientras tanto y en paralelo, realizó sus primeras excavaciones y puso a rodar el negocio que le daría fortuna: el comercio de antigüedades. Su centro de operaciones habría sido la casa ZavaletaEsteves. $^{5}$

Volviendo al cargo de comisario, no hay fuentes de archivo que avalen este dato. Esta función sí fue ejercida por Lucas Zavaleta, ${ }^{6}$ primo de su padre

5 Hoy propiedad de la familia Mirande, se presenta turísticamente como la primera casa de veraneo de Tafí.

6 Posteriormente, el nombre Lucas Zavaleta aparece asociado a importantes funciones en la Policía Provincial, a comisiones de obra e infraestructura y a cargos de Secretario del Colegio Electoral o del Senado; pero habiendo al menos dos descendientes con ese nombre, no es posible determinar de cuál se trata en cada caso. 
("Lucas Zavaleta asume el cargo de comisario", 1880). El distrito de Tafí tenía entonces comisarías en Tafí y en Colalao; mientras que en Amaicha se instaló recién en 1902, por reclamos de los vecinos. Por su parte, Fuerte Quemado -lugar del supuesto cargo de Manuel- era parte del distrito de Santa María, Catamarca. Otra cuestión a tener en cuenta es que, de haberlo ocupado, se trataría de un cargo intermitente, ya que hasta 1885 (con 23 años) Manuel sostenía obligaciones comerciales en la capital; y que luego de comenzado su circuito de ventas arqueológicas, se dedicaría a viajar frecuentemente a Buenos Aires y al extranjero. Más allá de esto, el foco debe ponerse en su pertenencia social, ya que cualquier cargo que pudiera haber ocupado sería -en todo caso- consecuencia de aquella. Fue su posición en la élite tucumana y sus relaciones familiares las que le permitieron acceder a las vinculaciones necesarias para desarrollar su actividad en el campo local. Pero, sobre todo, le posibilitaron articular con otros actores fuera de ese contexto y vender las piezas en el terreno nacional e internacional, sin lo cual las tareas de excavación no hubiesen prosperado. Así, sus relaciones familiares, capital social y sus propias competencias personales fueron fundamentales a la hora de trazar redes con agentes e instituciones, especialmente en Buenos Aires, lo que indica además la trascendencia geográfica de los vínculos entre los sectores de poder tradicionales provinciales y el poder central.

\section{El comienzo}

Zavaleta reunió su colección inicial en la primera mitad de la década de 1880 y consciente sobre dónde dirigirse, orientó sus esfuerzos hacia las instituciones de Buenos Aires que podían interesarse en sus mercancías. En enero de 1885 el periódico El Orden de Tucumán anunciaba haber examinado las colecciones que este "estimable joven" de 23 años había recogido en sus excursiones "por el Aconquija". La nota destacaba el valor científico de los 101 objetos de "órden íncásico" e instaba imperativamente al gobierno nacional a recompensar al joven por "estos tesoros de la tierra y del hombre antiguo". Se mencionaba que el presidente Roca había ofrecido una buena suma de dinero por el fósil del conjunto, semejante a "un archegosaurus de la clase de los reptiles del órden de los ganocéfalos, tan conocidos por la ciencia" ("Colecciones científicas”, 1885). Luego de la rimbombante presentación, el diario no podía menos que felicitar al joven "por el brillante resultado de sus excursiones y desearle como legítimo corolario un nombre que agregar a la ciencia criolla y una mejor cantidad de nacionales de curso legal (aunque sea) para el bolsillo, á guisa de cordial contra las agitaciones de la esploracion" (“Colecciones científicas”, 1885).

A fines de febrero, el mismo medio informaba que el gobierno enviaría a estudiar la colección de curiosidades, ofrecida en venta al Museo Nacional a través del Ministerio de Instrucción, lo que indica la rápida respuesta de este. Esta primera negociación anunciaba además parte de la estrategia que seguiría Zavaleta, consistente en gestiones directas y multifocalizadas: además de acudir a la prensa, consultó la opinión de Florentino Ameghino (Zavaleta, 1885a) utilizando textualmente su respuesta (Ameghino, 1885) en la propuesta de venta al ministro Eduardo Wilde (MJCIP, 1885, pp.1175-1176). Este encargó examinar la colección a Hermann Burmeister, entonces director del Museo, quien lo hizo primero con Domingo F. Sarmiento y luego con Andrés Lamas (Burmeister, 1885).

Burmeister confirmó que el gliptodonte de la especie Hoploplorus aún no había sido descripto, pero que la pieza estaba demasiado deteriorada para lograr una buena restauración (MJCIP, 1885, pp. 1177 1178); a la vez mencionó que en 1880 José Posse le había ofrecido en Tucumán uno mejor conservado, al que debió rehusar por el riesgo de transportarlo. Monguillot, preparador del museo, especificaba que la pieza había "sido dividida en cuatro grandes pedazos para facilitar su conducción" (MJCIP, 1885, p. 1182), desestimando el valor del fósil (vedette de la colección en la argumentación de venta). Se propuso así solo un pago indemnizatorio de 500 pesos moneda nacional por la extracción y transporte a Buenos Aires. Mayor interés despertó la colección de piezas de piedra, barro y metal de distintos puntos del valle y los cráneos (dos de Tolombón, dos de

7 Provenientes de Animaná, Molinos, Angastaco, San Carlos, Cafayate y Tolombón (Salta); Valle de Tafí, Amaicha, El Bañado (Tucumán); y Fuerte Quemado, Santa María, San José, Andalhuala, Aspajango y Andalgalá (Catamarca). 
San José y uno de El Bańado). Sin embargo, aunque fue muy halagada, se aconsejó pagar solo 4000 pesos moneda nacional por el conjunto, monto muy inferior a los 15000 pesos oro pedidos por el vendedor.

La valuación, estimada por Lamas, fue justificada con un listado de precios por unidad (MJCIP, 1885, pp. 1177-78). Sin criterios explícitos, puede inferirse que se basó en el tamaño, material, originalidad y complejidad de las piezas. Las pequeñas o "comunes" (puntas de piedra, objetos de barro, prendedores de cobre) oscilaban entre los 8 y 15 pesos. El monto ascendía en relación al mayor porte o rareza; hachas, piezas de cobre, morteros y cráneos rondaban los 30 pesos y los objetos más caros eran un mango de espada de 60 pesos, un puco de 200 y cinco tinajas de 300 cada una (MJCIP, 1885, pp. $1179-1182)$. Este punto es de gran interés porque plantea el problema de la traducción del valor "científico" de las piezas a otro económico y, finalmente, a un precio. Y porque esta operación fue definida por representantes del Estado.

La venta también planteaba un cambio de escala y localización respecto de las habituales transacciones en el campo, por el tamaño de la colección, la intervención de instituciones estatales y por ocurrir en el centro metropolitano. Hay que señalar también que se producía en el marco de una primera etapa de políticas patrimonializadoras, comenzada el año anterior con la ya mencionada nacionalización de la Biblioteca y el Museo Público, de cuya comisión de negociación también formaba parte Lamas. En aquella oportunidad, como en esta, la "conveniencia pública” se transformó en un argumento central, en el marco de un Estado que se apropiaba del pasado, tal como se detalla en el decreto de adquisición de la colección (MJCIP, 1885, p. 1183).

Este primer episodio es importante de cara a las posteriores acusaciones que se harían a Zavaleta de provocar el alza de precios en el territorio, porque muestra cómo la definición del valor de mercado era efectuada por el mismo Estado y no por el huaquero. De hecho, Zavaleta explicitó su decepción por el pago al ministro, aunque decidió "renunciar al lucro que podría obtener" en atención a este y para colaborar con el patriótico motivo de "que no salgan de esta tierra objetos preciosos que puedan servir a la historia geológica y aun política de mi patria”, motivo que olvidaría rápidamente. Regateando, propuso cederlos por 5000 pesos, (MJCIP, 1885, p. 1179). La colección fue recibida en la casa particular de Monguillot y el 3 de marzo, contra entrega de las piezas, se extendió la orden de pago, incluido en el presupuesto anual de Instrucción Pública. (MJCIP, 1885, p. 1184).

Pese a no recibir lo esperado, el pago fue lo suficientemente convincente como para motivar a $\mathrm{Za}$ valeta a seguir formando colecciones, y esta primera negociación sirvió como puntapié inicial para una larga y fructífera carrera de intercambios institucionales. De este modo, el Estado legitimó el comercio de antigüedades y operó como agente formador de precios, confirmando la conversión de las piezas en recursos económicos y por lo tanto, en una potencial fuente de riqueza.

En paralelo, Zavaleta bautizaba su fábrica de hielo como "El Gliptodonte" y elevaba a la Sala de Representantes de Tucumán un pedido de exoneración de impuestos (Zavaleta, 1885b), argumentando que los "establecimientos de este género merecen la protección de los Poderes Públicos, por la necesidad sentida que viene a llenar y por las contingencias consiguientes a un negocio poco conocido y de un precedente fatal para los especuladores", tema en debate desde 1858 (Páez de la Torre, 2014). ${ }^{8}$ Es evidente que Zavaleta poseía desde muy joven la instrucción y competencias para conducirse correctamente en el mundo de los negocios y de la política, y que su capital social y simbólico le permitía establecer contacto directo con personalidades de alto rango. El ejemplo más notorio es un significativo documento encontrado en el Archivo General de la Nación: una carta personal enviada al presidente Roca, un tiempo después de su primera venta:

\section{Al Exmo. Señor Presidente de la República} Brigadier Don Julio A. Roca:

Saludo al Sr. Presidente y amigo:

8 Ese año el gobernador Marcos Paz solicitó a la Sala de Representantes gravar la nieve de los cerros a quienes la comerciaran, exonerando al consumo local. Finalmente se la nieve fue declarada propiedad pública, cobrándose 4 reales a cada carga de nieve que ingresara a la ciudad para consumo público (Páez de la Torre, 2014). 
Deseo mucho se encuentre bien en compañía de su Señora y toda su distinguida familia; ud. me dispensará señor la confianza (y es porque lo quiero de corazón) hace tiempo que pensaba hacerlo pero mis grandes ocupaciones me han privado de este gran placer; Señor, ya tengo perfectamente bien instalada mi Máquina de Hielo. Es la única en nuestra provincia y le debo a ud. en su mayor parte lo que nunca se borrará de mi corazón.

Con este mismo correo le remito una pequeña encomienda (que es carne salada de Tafí) para que se sirva tomar al nombre de su amigo.

Puede ordenar a su amigo en lo que guste que será un placer para él serle en algo útil. Sin más por ahora su amigo y S.S. Manuel B. Zavaleta.

Casa de la Calle Las Heras $N^{\circ} 57$. Tucumán (Zavaleta, 1885c).

El tono personal, la redundancia en nombrarse "amigo" y la afectividad explícita en su declaración, "lo quiero de corazón", podrían indicar la existencia de un vínculo cercano, aunque no he encontrado datos que avalen esa hipótesis. Había mucha diferencia de edad entre ellos (Roca era 20 años mayor), su relación familiar era lejana (Roca era primo político tercero de Avellaneda -primo de la madre de Manuel-) y Roca visitó Tucumán, luego de haberse ido, por un breve lapso durante 1883. No obstante, es curioso que un joven tratase tan coloquialmente y sin distancia jerárquica al entonces presidente de la nación, siendo un completo desconocido. Por otra parte, la mención en El Orden al interés de Roca por el fósil hace posible inferir que hubiera existido alguna conexión entre ellos, aunque más no fuera circunstancial, quizás en la visita de 1883 recién mencionada.

Si este vínculo resulta de interés en el contexto de esta primera venta, mucho más lo sería para 1899 , cuando durante el siguiente mandato de Roca, Zavaleta recibiría una extraordinaria retribución por su cuarta venta al Estado, como veremos más adelante.

\section{Museo Nacional y Museo de La Plata. Ventas y disputas}

La venta de 1885 motivó entusiasmo en el ambiente científico, por la inversión que el gobierno nacional había realizado a favor de su museo, aunque esto fomentó a su vez la puja existente entre este y el de La Plata. Según Farro (2008) los presupuestos aprobados entre 1878 y 1884 habían beneficiado al Museo Público, permitiéndole sostener personal y otorgando sumas para colecciones, libros, expediciones y para publicar los Anales del museo; mientras que para el Museo de La Plata se contempló un menor presupuesto, teniendo que sustentar el propio Francisco Moreno gastos de preparación, transporte, expediciones, compra de libros e instrumentos. ${ }^{9}$ En este contexto, Moreno planeó un urgente viaje al NOA para adelantarse a Burmeister, previendo que a este "se le va a abrir el apetito con lo que tiene Zavaleta y temo que envíe a algún acólito suyo" (Moreno, 1885). Moreno estaba en lo cierto: pese al descontento con el pago recibido en 1885 , Zavaleta vendió una nueva colección paleontológica y arqueológica al Museo Nacional en 1887 por la suma de 10000 pesos moneda nacional, en teoría "compuesta, en su mayor parte, de objetos de inestimable valor histórico, trabajados por los hombres que habitaron los valles de Calchaquí, en las Provincias de Salta, Tucumán y Catamarca, siglos antes del descubrimiento" (MJCIP, 1887, p. CXXXIX).

La Memoria del museo de ese año no detalla el contenido de la colección, debido a que los cajones fueron abiertos meses después. El Libro de Inventario solo indica la compra de la "segunda colección de Antigüedades de Los Indios Calchaquíes traída por D. Manuel B. Zavaleta. Los objetos han sido encajonados y colocados en este estado en la biblioteca

9 La disputa institucional se prolongó en el tiempo, con distintos episodios. En 1893, luego de 20 años de amistad, Moreno rompería públicamente relaciones con Carlos Berg (siguiente director del Museo Público) con quien compartían críticas hacia Burmeister y por quien Berg había rechazado el puesto de vicedirector. Moreno acusaría a Berg de boicotear el Museo de La Plata y omitir los trabajos allí producidos. Al ańo siguiente, Berg rechazaría una propuesta de "pacificación” de Moreno -quien planteaba colaboración y préstamos entre las instituciones-. 
bajo la mesa grande. Los cajones son de trece en todo" ("Libro de Inventario del Museo Nacional", 1887). A diferencia de la venta anterior, la información sobre esta es escasa y no se publicaron cartas ni informes sobre su gestión. El ministro Filemón Posse envió directamente una carta al director con copia legalizada de la lista de 275 objetos (Posse, 1887). Los cajones depositados en la biblioteca debieron abrirse luego "a causa de muchas polillas saliendo de los cajones porque los objetos han sido envueltos por el vendedor en lana sucia”, ("Libro de Inventario del Museo Nacional”, 1887). Burmeister no solo denunció la falta de cuidado del vendedor, sino el hecho de que "todos los objetos son duplicados de la colección anterior, y que el público no pierde nada si no vé por el momento más que ésta”. Además aprovechó para reclamar al gobierno que se hiciera efectiva la promesa de cesión de dos salones de la Universidad, por el aumento de existencias (MJCIP, 1888, p. 1060), planteando la contradicción de un Estado que invertía en piezas arqueológicas (sin revisarlas), pero no en un lugar donde guardarlas.

Desde allí, los aspectos negativos del trabajo de Zavaleta comenzaron a utilizarse como argumento. Farro (2008) señala que Moreno intentó que el gobierno le financiara una excursión a la zona calchaquí, argumentando que significaría un gasto mínimo (2000 pesos moneda nacional) frente a los $13500^{10}$ recién pagados a Zavaleta y destacando la diferencia entre el interés "de estudio" de su museo y el de los que "proyectan con miras de interés pecuniario" (Moreno, 1887). No obstante, también debe señalarse que al no ser aprobada la expedición, Moreno terminó comprando a Zavaleta una tercera colección de 400 piezas por 16500 pesos moneda nacional, que había sido rechazada por Burmeister. La compra fue justificada por la carencia de ese tipo de piezas en el museo; aunque aclarando que de poder realizar exploraciones bien dirigidas se evitarían compras innecesarias o se las limitaría a objetos

10 La diferencia entre las cifras oficiales y las citadas por Moreno corresponderían, según Farro (2008), a que las primeras están expresadas en pesos moneda nacional "oro". Para 1887 se había suspendido la convertibilidad de la moneda nacional el peso oro (se retomaría en 1899) aunque a un cambio de un peso oro $=2,27$ pesos moneda nacional. únicos. Nuevamente, la apertura de los cajones trajo malestar: había objetos falsificados y confusión de datos de procedencia. Este episodio plantearía una profunda discordia entre el Museo de La Plata y Zavaleta y orientaría a la institución a realizar sus propias expediciones al NOA entre 1888 y 1902 (Methfessel a Pilciao, Santa María y alrededores en 1888-89; Ten Kate al Valle Calchaquí en 1893; Gerling a Salta y Jujuy en 1898; todas con apoyo de Lafone Quevedo en el territorio).

Zavaleta consultaba a Ameghino cada vez que ofrecía una colección y este respondía benéficamente, limitándose a describir el valor científico y sin expedirse sobre el económico (que era lo que pretendía Zavaleta). El "sabio" señalaba una y otra vez la dificultad de esa estimación, poniendo de relieve la ambigüedad en esa esfera, que hacía que cualquier definición fuera arbitraria:

Yo no sé lo que esto pueda valer, pues $\mathrm{Vd}$. sabe que esas cosas no tienen un valor real, sino simplemente relativo. En manos del que estudia y desea descifrar los problemas etnológicos de las razas o los pueblos que habitaron nuestro suelo en las épocas pasadas, son impagables, para el vulgo no valen nada. Todo lo que puedo asegurarle en conciencia es que, como colección de antigüedades calchaquíes, es inmensamente superior a todo lo que hasta ahora he visto como de la misma procedencia (Ameghino, 1888).

La cita resume el problema de traducir las piezas a un valor de cambio. Asimismo, lo "relativo" de las diferentes valoraciones según cada agente (los científicos y el "vulgo") permite, siguiendo a Baudrillard (2011) comprender la asociación entre la función social distintiva de las cosas y la función política e ideológica que la sustenta; y cómo su manipulación o consumo se correspondían con mecanismos de discriminación y prestigio surgidos de sistemas de valor y jerarquías sociales.

Pero pese a su negativa a cuantificar precios, Ameghino era una autoridad y Zavaleta sostuvo esa relación de distintos modos. Primero, adulándolo: 
Muy contrariado por el viejo Director del Museo [Burmeister], espero, después de algunos años encontrarlo a $\mathrm{Vd}$. al frente, $\mathrm{y}$ así, sin émulos y persecución conseguir alguna vez el premio a mis afanes. Llevo la idea de gastar cuanto poseo; y si alguna gloria obtengo, será exclusivamente suya, pues Vd. me da aliento y esperanza. Vd. es pues, quien merece estar al frente de nuestro $\mathrm{Mu}$ seo, en este país nuevo y progresista (Zavaleta, 1888a).

Segundo, ofreciéndole material de su interés. Sin poder llevarle un prometido gliptodonte (Zavaleta, 1888b), le aportaría una serie de fragmentos que Ameghino presentaría como "fósiles miocenos de Tucumán y Catamarca” (Ameghino, 1891). Ameghino sumaría los fósiles de Zavaleta a la historia de hallazgos paleontológicos del valle como un último aporte que permitía reconocer especies y confirmar las edades atribuidas previamente a los yacimientos. Más aún, denominó Sphenotherus Zavaletianus a un ejemplar desconocido, para honrar a su descubridor (Ameghino, 1891).

Tercero, participando en sus disputas académicas. En 1889, Zavaleta pidió a Ameghino opinión sobre una nueva colección (según este "la tercera o cuarta vez que me hace idéntico pedido"). Su dictamen fue inmejorable: la colección superaba a las precedentes "por lo variado y escogido de las piezas" y sus motivos iconográficos. Ameghino profetizaba con razón que esta no sería la última colección que Zavaleta formaría y le aconsejaba reunir todo su material en un solo punto que no fuera La Plata:

Ese establecimiento no ofrece la más mínima garantía de seriedad, pues está en manos de un megalómano que sueña y delira grandezas, que con su continua charla de frases estereotipadas, huecas y sin sentido, está poniendo en ridículo a nuestro país en el extranjero, donde por desgracia, a menudo, por una mala muestra, se juzga de todo en sentido desfavorable. Ese establecimiento es un mare magnum, un caos, del cual sólo podría dar una pálida idea el cambalache de las Tres bolas. Allí los objetos pequeños se hacen más sutiles que el humo y los grandes adquieren un aspecto uniforme: la forma esférica, símbolo de la estabilidad.

Sería de preferir que por todos los medios posibles tratase usted de reunir todas sus colecciones en el Museo Nacional de Buenos Aires. Es cierto que allí no se dispone de local para exponerlas, pero a lo menos serán guardadas cuidadosamente, pues la austeridad del Director de ese establecimiento no lo mueve a formar trofeos de objetos, ni se da bombo, ni estampa comunicaciones hechas con grandes frases rebuscadas y tendenciosamente inspiradas por el propósito de pedir fuertes sumas a los poderes públicos; ni hace montar en costosos armazones enormes piezas que no sirven ni para arrojarlas a la basura, destinadas a que sean contempladas por aquellos senadores y diputados que no entienden la cosa, a fin de que abran la boca $\mathrm{y}$ acuerden luego las partidas solicitadas (Ameghino, 1889). ${ }^{11}$

Ameghino lo autorizó a utilizar sin restricción su catártica disquisición contra el museo y el "vulgar charlatán” que lo dirigía, y Zavaleta la publicó completa en la prensa, involucrándose públicamente en las rencillas académicas internas de Ameghino con Moreno. Pero que Zavaleta tomara posición en disputas del círculo científico de Buenos Aires, alineándose con la parte que lo beneficiaba para desprestigiar a la otra, no es ilógico si se tienen en cuenta las crecientes críticas que desde La Plata vertían sobre su persona (sobre todo después de la venta de 1888). Asimismo, Zavaleta compartía con el sabio su preocupación sobre la intensa actividad de los corresponsales de La Plata en los valles, donde "más de 100 extranjeros en la compañía de Lafone en busca de objetos y fósiles para Moreno (y pagan los ojos

11 El compilador aclara: "Esta carta fue publicada por el diario "Fígaro" de Buenos Aires, tal como había sido redactada por su autor, el día 28 de junio de 1889, y por "La Nación" de la misma ciudad, mutilada, suprimiendo de ella los párrafos más sabrosos: los que describen el cambalache de las tres Bolas, o sea: el Museo de La Plata. V.J.T” (Torcelli, 1914, p. 1011). Esto evidencia tanto el cuidado de La Nación hacia Moreno como la exposición que hizo Zavaleta del conflicto. 
de la cara por cualquier cosa)" (Zavaleta, 1889), estableciéndole competencia en su propio territorio. $\mathrm{Al}$ respecto, la información que aporta Farro (2008, pp. 233-234) sobre la movilización de corresponsales, empleados y contactos provinciales para comprar piezas y ganarle al "loco Zabaleta", que había subido la plaza "de manera que los indios conocen el interés y piden mas por los objetos" (Carro, 1894), demuestra cómo el Museo de La Plata participaba de la competencia, aunque denunciando (desde la perspectiva opuesta a la del huaquero) que era este el responsable de la misma, así como del aumento de precios.

Pero que "el loco" hubiera subido la plaza o que los hombres de Lafone pagaran "un ojo de la cara" por las piezas son acusaciones cruzadas que, aunque enunciadas desde lugares antagónicos, son caras de la misma moneda. Una lectura crítica permite comprender que la competencia fue alimentada por ambos lados, con prácticas de intercambio similares. Y que la participación de los científicos los hace corresponsables de sus efectos, más allá de que discursivamente se legitimaran en preceptos de cientificidad y en un desprecio explícito hacia el mercado de antigüedades, contraponiendo el objetivo "puro" del conocimiento a los contaminantes intereses pecuniarios de los comerciantes (Tolosa, en prensa). La consecuencia directa de esto fue que los sujetos locales reconocieran la potencialidad económica de las piezas y se dispusieran a participar del circuito de intercambio con una relativa agencia en la definición de los precios, lo que acarreó un perjuicio para los científicos, acostumbrados a ocupar una posición privilegiada en un tipo de intercambio asimétrico, basado en las necesidades locales y en el "desconocimiento" de los pobladores sobre el valor de las piezas (Tolosa, 2014). En este sentido, podría decirse que lograron un rol más "igualitario" en las condiciones de negociación, aunque este aspecto "positivo" no compensó la pérdida de recursos culturales que sufrieron. Fue así que los científicos solicitaron intervención del gobierno sobre el "tráfico y comercio de bric à brac":

[Q]ue el congreso de la nación se preocupe en ver de qué modo se salvan las antigüedades del país de la mano destructora de los mercaderes en estas cosas, que destruyen el 75 por ciento de lo que encuentran, y el 25 que queda se logra en las peores condiciones para ser utilizado por el estudiante; ya porque se lleva al extranjero, ya porque carece de filiación [...]. Es llegado pues, el momento en que todos reunan sus esfuerzos al objeto de proteger nuestras antigüedades del vandalaje que los amenaza y destruye (Lafone Quevedo, 1897).

Sin embargo, el gobierno no solo no evitaba el comercio de antigüedades sino que participaba del mismo. Tanto el Ministerio de Instrucción como el Congreso fueron agentes activos en su desarrollo negociando y adquiriendo colecciones, especialmente a Zavaleta, blanco de las críticas. Por otra parte, y volviendo al tema de las disputas entre museos, cabe preguntarse también cuál sería la incidencia del plano político en las "alianzas y guerras científicas" (Ametrano et al., 2012) en relación con las diferencias entre la provincia de Buenos Aires y la nación, apaciguadas (pero no extintas) al federalizarse la capital. ${ }^{12}$ En este marco, la "falta de apoyo" del gobierno nacional al Museo de La Plata acusada por Moreno se contradice con las condiciones de su flamante edificio, opuesto diametralmente a la terrible situación del Museo Nacional, "preferido" por el gobierno con la compra de estas colecciones. Esto permite a su vez problematizar el destino de las inversiones del gobierno, que seguía gastando en colecciones en lugar de resolver los problemas estructurales de los repositorios. ¿Se debían estas prácticas inorgánicas a la falta de planificación? ¿Las compras realizadas

12 Mientras Burmeister había sido preferido por Avellaneda, y prosiguió en su cargo hasta su muerte avalado por el gobierno nacional, Lafone y Moreno fueron cercanos a Bartolomé Mitre, con poder en la provincia, considerado una autoridad en arqueología y consultado por el Congreso sobre colecciones y libros. La Nación, su órgano de prensa, publicó los informes de las expediciones de Moreno, que según este el Ministerio del Interior de Roca silenciaba, y las notas científicas de Lafone. El propio Mitre gestionaría el nombramiento de Lafone como encargado de la sección "Arqueología y Lingüística” del Museo de La Plata en 1898. Moreno, por su parte, había tenido menos atención del Partido Autonomista, lo que se observa en la falta de respuesta del gobernador Dardo Rocha cuando intentaba el traslado de su Museo a La Plata. 
a Zavaleta perseguían el beneficio de la institución o el de aquel? Si bien no es posible responder estas preguntas, sí lo es señalar que fue el poder político nacional el que permitió a este "enamorado de la arqueología y la antropología” realizar las cuantiosas ventas que vendrían.

\section{Retirada y paseo por París}

A pesar de los problemas mencionados, Zavaleta ofreció en 1886 una nueva colección de1800 objetos $^{13}$ a la que Quiroga le asignó el "mérito indiscutible de contener numerosos objetos de localidades dentro y fuera de los valles, de donde aún no se habían reunido en grupo objetos que por su número y cantidad, nos hablasen a las claras de la cultura local" (Quiroga, 1896, p. 179). Una novedad importante respecto de las compras anteriores, orquestadas a través del Ministerio de Instrucción, es que a partir de aquí las negociaciones se harían dentro del marco legislativo, marcando un cambio en la política de adquisición patrimonial, que ahora pasaba a requerir del debate parlamentario y de la sanción de una ley. Estas nuevas prácticas parecen corresponderse con el viraje hacia una política patrimonial más centralizada, enmarcada en la consolidación del proyecto nacional durante el gobierno de Roca. También cabe señalar que en ese momento Marco Avellaneda, hermano del expresidente y primo de Zavaleta, era presidente del Senado.

El 17 de junio se giró a la Comisión de Peticiones de Diputados la propuesta de venta de la "colección de arqueología y antropología” (Congreso de la Nación [CN], 1896a) de Zavaleta. Días después, la Cámara acordó repentinamente la devolución de la propuesta, por solicitud del oferente $(\mathrm{CN}$, 1896b). La retirada coincidió con la presentación de la colección en el extranjero, una apertura al negocio internacional. Poco después, la prensa parisina anunciaba que este "archéologue de la République Argentine, est arrivé à Paris, venant de Buenos-Ayres avec une collection de plus de deux

13 Las piezas procedían de Tafi, Amaicha, Colalao, Cafayate, San Carlos, Molinos, Chiquimí, Cachi, Tolombón y Quilmes. Había 86 ídolos, 75 cráneos, 143 urnas y 143 pucos, aunque estos procedían de distintos lugares que las primeras. mille pièces d'archéologie et d'anthropologie concernant la race préhistorique des Calchaquis, qui habita les régions andines de la République Argentine" ("Noticia sobre arribo de Zavaleta"). La exposición gratuita estuvo abierta al público en enero en dos salas del Trocadero, asignadas por el Ministère de l'Instruction Publique (Petitjean, 1897). A fines de septiembre, una extensa e ilustrada columna comentaba:

M. Zavaleta se propose de faire connaitre à notre monde scientifique cette collection rare qu'il lui a fallu dix- huit années de recherches et de grands sacrifices pour rassembler et qui constitue un véritable musée attestant le développement relatif des civilisations préhistoriques du nouveau continent et particulièrement celle de ce peuple artiste, guerrier et industrieux que furent les Calchaquis. Cette collection a été exposée à Buenos- Ayres au mois de juin dernier. Elle a excité l'intérêt le plus vif dans le monde savant argentin qui, d'ailleurs, a été unanime à regretter qu'elle quittât la République argentine pour Europe, d'où elle ne reviendra sans doute pas. L'ancien président, le général Mitre, dont on connait les travaux littéraires et les études ethnographiques, a dans une lettre adressée à $\mathrm{M}$. Zavaleta manifesté, en même temps que ce regret, "l'espoir que partout les savants reconnaitront la valeur archéologique de cette collection, véritable révélation de la civilisation éteinte des Calchaquis, qui d'après les monuments préhistoriques, paraît antérieure à la conquête quichua" (Guilaine, 1896).

No he podido confirmar a qué exposición se refiere la cita, ya que el momento señalado coincide con el ingreso de la propuesta de venta al Congreso, luego desistida. Pero las contradicciones y enunciados incomprobables son frecuentes, lo que permite pensar que corresponderían más a una estrategia publicitaria que a hechos reales. Sobre la carta de Mitre, es probable que hubiera estado dirigida a Miguel Cané, embajador en Francia, quien recibió a Zavaleta. Esto indica que sus contactos no se limitaban por cuestiones ideológicas ni partidarias; su estrategia 
era amplia y recurría a distintos referentes de autoridad para argumentar el valor de su material.

La posibilidad de que la colección "no volviera" al país apelaba a ambas naciones -invocando el interés de Francia y el patriotismo de Argentina- y se convirtió en un elemento central en el juego de $\mathrm{Za}$ valeta. El temor a la pérdida de las colecciones sería instalado y repetido por distintos actores nacionales como una fórmula, incluso increpando al mismo huaquero: "debemos recordar[le] sus deberes y sentimientos de argentino para que esta colección quede en el país, figurando en los estantes de nuestros museos, porque de otro modo se van al extranjero los elementos seculares de estudio de nuestra prehistoria” (Quiroga, 1896, p. 210).

Para Zavaleta, París ostentaba la autoridad científica internacional y buscaba ese respaldo. Por su parte, los investigadores franceses consideraron que eran sus colecciones las que habían motivado el debate y los artículos sobre la población calchaquí (Société des Americanistes de Paris [SAP], 1897, p. 206) de Lafone, Quiroga, Burmeister, Ameghino y Berg. Esta confusión también podría indicar un buen trabajo publicitario de Zavaleta sobre su posición en el campo científico argentino, que los franceses conocían solo parcialmente. Es notorio también que en paralelo a la exposición la Société, presidida por E.-T. Hamy, criticara un trabajo de Ambrosetti por sus "dessins assez médiocres, ce qui es profondément regrettable, la fidélité de la reproduction aidant singulièrment à l'identification et à l'explication des figures et des objets ethnograpiques" (SAP, 1897, 206), sugiriendo que era mejor estudiar esa "raza" a través de sus colecciones, dos formadas por Zavaleta (la del Museo Nacional y la que se exponía) y la tercera del "institut argentin dont le directeur est justement M. Ambrosetti” (SAP, 1897, p. 206).

La supeditación de los científicos argentinos a los "descubrimientos" de Zavaleta pudo haber contribuido a la tensión existente entre ellos, desconocida en Francia. Por su parte, en Argentina se profundizaba la diferenciación respecto de los científicos extranjeros: así, Ambrosetti ironizaba sobre los errores interpretativos de los franceses, debidos a su estudio sobre colecciones, sin trabajo de campo:
[D]espués de leer esto, uno queda convencido cada vez mas de que la arqueología de cualquier país es necesario estudiarla en el mismo territorio donde se hallan los objetos, haciendo excavaciones y explorando personalmente los yacimientos. Si el doctor Hamy hubiera dado unas cuantas paladas en la región calchaquí, no se habría cansado de encontrar huesos de niños dentro de las urnas; esto demuestra como las colecciones recogidas sin método científico no pueden servir sino para excitar la fantasía y formular hipótesis sobre hechos reales é indiscutibles. Que nosotros al encontrar cuerpos de niños dentro de las urnas mencionemos la existencia de antiguos sacrificios humanos, nada tiene de particular [...] Pero sustituir el cuerpo del niño cuyos huesos encontramos por una ofrenda de chicha, es demasiado (Ambrosetti, 1897, p. 65).

Coronando el éxito de la exposición de Zavaleta, se publicó un largo artículo que -a diferencia de los "mediocres" dibujos de Ambrosetti- contaba con excelentes ilustraciones de los objetos y caracterizaba a los calchaquíes como "l'une des plus intéressantes races de l'Amerique du Sud" por sus monumentos, necrópolis, petroglifos y posibles vinculaciones con otras civilizaciones (Landrin, 1897, p. 292). El artículo también dejaba claro que era la Société des Américanistes la que legitimaba los "documentos" expuestos y determinaba su importancia para ampliar investigaciones científicas previas.

Así, Zavaleta no solo cumplía el objetivo de "consagrar" su colección en la cúpula del americanismo mundial, sino que conseguía el primer puesto en el podio de los arqueólogos argentinos ante el círculo parisino, tensando más aún las relaciones locales. Pero pese a los reconocimientos, la colección no fue vendida a Francia. Más adelante Cané recordaría que si bien la "asiduidad" de Zavaleta y la buena acogida del gobierno francés habían logrado el interés de las revistas científicas y la visita de "todos los hombres de ciencia de París" a la exposición, y que los especialistas aconsejaron al gobierno francés comprarla, "éste no accedió a ello, solamente porque creyó que el precio sería demasiado elevado, y 
no estaba en aptitud, en ese momento, de hacer esa adquisición" (CN, 1900, p. 561).

La excursión al extranjero tuvo sin embargo sus beneficios; la efectividad del discurso publicitario, instalado en los intersticios del sistema de comunicación científico, permitió a Zavaleta abrir la puerta al circuito comercial internacional. A la vez, pudo utilizar el "éxito" parisino como argumento en sus siguientes operaciones. La colección, comenzada con los 1800 objetos apuntados por Quiroga, seguiría aumentando y sería ofrecida en venta al gobierno nacional en 1899, con 2009 piezas.

\section{La escandalosa venta del año 1899}

Para poder dimensionar la particularidad de esta tercera venta con destino al Museo Nacional, corresponde mencionar las condiciones en que esta institución se encontraba, y profundizar sobre las mencionadas inversiones "contradictorias" que el Estado realizaba. Carlos Berg, que asumió la dirección en 1872 y reorganizó el museo con impronta naturalista, por sobre la arqueológica y antropológica previa, denunciaba la insuficiencia de espacio y de presupuesto (MJCIP, 1894, p. 206) que impedían exponer y estudiar las colecciones (entre ellas las ya adquiridas a Zavaleta) que se acumulaban en la biblioteca. Berg señalaba haber heredado un museo descuidado por la poca inversión hecha por Burmeister, quien padecía de "cierta idea de economía mal entendida", inadecuada para un museo nacional: "empleaba el material más ordinario y barato, cuando, en verdad, ha podido adquirir muebles, útiles y colecciones, con las cantidades que anualmente quedaban á favor del establecimiento" (MJCIP, 1893, p. 232).

Fue justamente en 1899 -fin de otra década crítica para el país- que Berg, ante una economía "en vías de normalizarse", renovó esperanzadamente el pedido de construcción de un edificio que permitiera guardar las colecciones, que seguían incrementándose (MJCIP, 1899, pp. 217-218). Ese mismo año llegaba de la zona calchaquí de Andalgalá la donación de Max Schmid consistente en 38 urnas funerarias; 106 vasijas de diversas formas y tamaños, 1 collar de cuentas de piedra; 1 ídolo de piedra, 3 de barro y 27 objetos diversos con "un valor intrínseco de miles de pesos" (MJCIP, 1899, p. 221); el donante prometía además próximas remesas, que solo costarían al museo gastos de transporte, aclaración que ilustra la dificultad de afrontar hasta los gastos más simples. La desastrosa situación edilicia ${ }^{14}$ y el bajo presupuesto resultan contradictorios con la compra de nuevas colecciones, sobre todo sin contar con las mínimas condiciones para recibirlas. Además, la afluencia de material calchaquí indica que no había urgencia en seguir invirtiendo en ello. Sin embargo, el gobierno prefirió comprar una nueva colección a Zavaleta antes que mejorar las condiciones estructurales del museo.

Entre las solicitudes particulares para la Sesión Ordinaria del 13 de mayo de 1899 ingresaba la propuesta de venta, que fue remitida a la Comisión de Peticiones (CN, 1899). El 24 de agosto el senador y miembro informante Eriberto Mendoza aconsejó la adquisición de las 2009 piezas. El argumento $(\mathrm{CN}, 1900$, p. 89$)$ se centraba en las opiniones científicas y de prensa sobre la colección, haciendo especial mención al paso por París, y presentaba un breve informe que Berg había confeccionado ante la desistida venta de 1896, enfocado exclusivamente en la conveniencia de retener la colección: ${ }^{15}$ "sería lamentable y hasta cierto punto vergonzoso, que las personas que dentro de la República se hubiesen de dedicar a semejantes investigaciones científicas tuviesen que recurrir al extranjero para examinar el material procedente de este suelo americano" $(\mathrm{CN}$, 1900, p. 561). El senador Cané confirmaba este riesgo, recordando el interés parisino y las intenciones del gobierno francés de adquirirla.

14 El problema continuó hasta 1914, ya con la dirección de Ángel Gallardo. El Ministerio ofreció una casa, en la esquina de Lima y Moreno, que permitiría organizar las colecciones mientras se disponía la partida para las obras.

15 La repetición del argumento de la "enajenación obligada al extranjero" está presente desde temprano en las declaraciones sobre colecciones, como en el proyecto de donación de Moreno para el Museo Antropológico y Arqueológico de Buenos Aires. Se mencionaba que Moreno había "resistido patrióticamente a estas tentaciones; no queriendo arrancar a su provincia del tesoro que posee". 
El problema era asignar precio a la colección. Los científicos consultados -Holmberg, Berg y Ameghino- no aceptaron tasarla, como antes hicieran Lamas y Burmeister. Y la comisión formada por estos últimos, "sin desconocer el valor científico de dicha colección y la conveniencia que ésta quede en el país" se declaraba ahora "inhabilitada para poder fijar su valor pecuniario, por tratarse de objetos que no son artículos de comercio, y por la falta de una base razonable para su avaluación”. (CN, 1900, p. 560). Esta toma de distancia de los científicos es concordante con la creciente demarcación del límite ético entre la actividad científica y la esfera comercial. No obstante, la incompetencia de los científicos fue resuelta velozmente por algunos senadores, que sorteando reparos establecieron -sin explicación sobre los criterios empleados- el precio de 50000 pesos moneda nacional "pagaderos en tierras públicas de las que haya disponibles en los territorios de la Pampa Central y Chubut, cuyo valor se determinará tomando como base el promedio obtenido en las últimas ventas que se han hecho por el Gobierno" (CN, 1900, p. 559). La propuesta resultó lo suficientemente resolutiva como para que se aceptase sin cuestionamientos, salvo el pedido del senador por La Rioja de incluir tierras de Santa Cruz y Río Negro, más convenientes para el gobierno, que no prosperó. Con una velocidad digna de destacarse, el 6 de septiembre el proyecto fue aprobado también en Diputados (CN, 1899, pp. 801-802), sancionándose la Ley 3799.

La repetición casi textual en los discursos de ambas Cámaras abordó los mismos tópicos: la unicidad de las piezas, la repercusión de la colección en París y su importancia para el estudio de las poblaciones autóctonas. Pero lo más llamativo es la cita a la opinión positiva de todos los especialistas, incluyendo a los que se manifestaban abiertamente en contra de Zavaleta, lo que permite preguntarse si los políticos desconocían el conflicto o lo invisibilizaban intencionalmente para favorecerlo.

Un punto novedoso fue la forma de pago, sobre la cual haremos varias observaciones. En primer lugar, es llamativo que Zavaleta -quien defendía el precio de sus colecciones- hubiera dejado "librada al Congreso la solución de todas estas cuestiones"
(CN, 1900, pp. 559-562). ¿Existía una particular confianza que le permitía descansar en que la resolución sería favorable? ¿Necesitaría "deshacerse" de la colección que ya venía transportando de un lado al otro, con los gastos que esto acarreaba? Lo cierto es que se mostró conforme, tanto con el precio como con la modalidad de pago.

En el debate parlamentario se planteó que el pago en tierras evitaba al gobierno el desembolso directo o los gastos de una operación de venta para pagar la colección en efectivo. El simple traspaso solucionaba también problemas de índole notarial por un valor "justo" para una colección que según Cané, "vale mucho más de lo que se va á pagar al señor Zavaleta, si este proyecto se convierte en ley" (CN, 1900, p. 561). Hay que señalar también que el pago fue considerado oficialmente una "permuta" entre piezas y tierras, lo que evitó que la posesión quedara sujeta a las normas generales de venta de tierras fiscales, por ejemplo la obligación de poblarlas; tampoco era posible negociar descuentos, lo que Zavaleta intentaría inmediatamente, sin éxito (Registro Nacional [RN], 1900, p. 473).

El promedio de las últimas ventas, del cual resultaba el precio, era de 2.722, 91 pesos por legua kilométrica para Pampa Central, el territorio mejor cotizado, donde Zavaleta eligió sus lotes. Luego de algunos ajustes, el 25 de agosto de 1900 se le adjudicaron “doce mil quinientas hectáreas en el lote $\mathrm{N}^{\circ} 20$ ángulo Sudeste del Lote $\mathrm{N}^{\circ} 13$ y la parte libre de adjudicación del lote $\mathrm{N}^{\circ} 18$, todos de la fracción A, Sección XIV del Territorio de La Pampa, y la superficie de cinco mil hectáreas en la mitad Este del lote $\mathrm{N}^{\circ}$ 15 , fracción B, Sección XIX del mismo territorio" (RN, 1900, p. 838).

El 1 de septiembre, un decreto señala que Zavaleta tenía un saldo de 18401 hectáreas y 35 áreas, que ubicó en los lotes 19 y 22, Sección X, fracción D (RN, 1900, pp. 108-109). Un nuevo decreto del 17 de septiembre contabiliza la cantidad total adjudicada a Zavaleta en 61209 hectáreas y un área $(\mathrm{RN}$, 1900, pp. 347-348).

La información es confusa, por la utilización indistinta de medidas (legua y hectárea) y por las 
Tabla 1. Tierras recibidas por Zavaleta del Estado como pago por su colección de 1899.

\begin{tabular}{|c|c|c|c|}
\hline \multirow{2}{*}{ Sección IX, Fracción D } & Mitad Sur del Lote 1 & 5000 ha & \multirow[b]{2}{*}{15000 ha } \\
\hline & Lote 10 & 10000 ha & \\
\hline \multirow{2}{*}{$\begin{array}{l}\text { Sección X, fracción D } \\
\text { (saldo del 1/9/1900) }\end{array}$} & Lote 19 & 10000 ha & \multirow{2}{*}{18400 ha } \\
\hline & Lote 22 & 8400 ha & \\
\hline \multirow{3}{*}{ Sección XIV, Fracción A } & Sectores NO, SO, y SE de Lote 11 & 7500 ha & \multirow{3}{*}{20000 ha } \\
\hline & Sector SE del Lote 18 & 2500 ha & \\
\hline & Lote 20 & 10000 ha & \\
\hline \multirow{2}{*}{ Sección XIV, Fracción D } & Lote 1 & 10000 ha & \multirow{2}{*}{20000 ha } \\
\hline & Lote 2 & 10000 ha & \\
\hline Sección XIX, Fracción B & Mitad Este de Lote 15 & 5000 ha & 5000 ha \\
\hline
\end{tabular}

aproximaciones en el traspaso de una a otra. ${ }^{16}$ Pero la falta de claridad también podría relacionarse con lo que parece ser una negociación espuria. Trataré de clarificar el asunto a partir de algunos cálculos. Si se toma en cuenta el valor oficial de la legua kilométrica en La Pampa (2.722, 91 pesos), los 50000 pesos del pago debían transformarse en 18,3627 leguas kilométricas de 2304 ha cada una (1 legua kilométrica $=2304$ ha), es decir, un total aproximado de 42 307, 66 ha. Si se suma el "saldo" de 18401 ha y 35 áreas otorgado el 1 de septiembre, resulta en un total de 60709,01 ha, es decir, 500 ha menos que las decretadas el 17 de septiembre (RN 1900, p. 161). La revisión del Catastro histórico de La Pampa, según los mapas de Thamm y Castellanos (1902) y de Córdova y Camuso (1922) indica que entre 1902 y 1920 Zavaleta era propietario de unas 60000 ha, cifra que se aproxima a lo expresado más arriba. No obstante, allí no figura el "saldo" de 18400 ha adjudicado el 1 de septiembre, que no estarían entonces comprendidas dentro de esas 60 000 ha. Hay que tener en cuenta, sin embargo, que la información catastral difiere según el momento y las posibles transacciones realizadas. Los datos que surgen de la triangulación entre el Registro Nacional de 1900 y el Catastro entre 1902-1920 se vuelcan en la Tabla 1. En gris se consignan las 18400 ha que figuran en el Registro pero no en Catastro:

16 Por ejemplo el redondeo de legua lineal en $5000 \mathrm{~m}$, cuando era de $4800 \mathrm{~m}$. No obstante, un cálculo oficial usaría medidas exactas.
Otra cosa a tener en cuenta es que de las 61209 ha pagadas por la nación, 55901 se encontraban arrendadas (RN, 1900, pp. 347-348), y como por ley se debían respetar los contratos hasta su finalización, se traspasaron los pagos del futuro arriendo al nuevo propietario, incluida la transferencia de cuotas abonadas anticipadamente al Estado por Salvador Pratto, Martín Larralde, Francisco Erreguerrena, Felipe Corbalán y Bautista Laherjuzan, que sumaban 4811, 02 pesos. También se endosaron a nombre de Zavaleta las letras de vencimiento posterior, se traspasó el contrato firmado por Erreguerena por 2055 ha y se renovó el de Larralde, de cuyas 20 000 ha arrendadas 10000 correspondían ahora a Zavaleta, a quien le adelantó los pagos de 1903 y 1904 (580 pesos cada uno) (RN, 1900, pp. $347-$ 348). Estas rentas constituyen así un beneficio extra sobre el pago de la colección.

Una última cuenta aporta el broche de oro. A la luz de los datos mencionados, podemos concluir que las 61209 ha inscriptas en el Registro Nacional equivalen a 26,566 leguas kilométricas, que a valor oficial (2722,91 pesos por legua) da como resultado 72 337, 93 pesos, es decir, 22 337,93 pesos más que lo expresado en la Ley 3799. Si se suman los montos por arriendo citados (sin contar utilidades futuras y montos no explicitados), el dinero recibido por la colección puede estimarse en un piso de 78 308,98 pesos, es decir, más de 28000 pesos sobre el valor estipulado por ley. Tomando en cuenta que esta información surge de decretos y comunicados del 
Registro Nacional, cabe preguntarse cómo se llegó a esta sustancial diferencia respecto de lo legislado. ¿Podría indicar algún tipo de negociación con el Poder Ejecutivo Nacional, a través del Ministerio de Agricultura?

La oscuridad se potencia en un contexto histórico en el que las tierras saqueadas a los indígenas pampa-patagónicos fueron la forma de capitalización de los financistas de la campaña, así como moneda de cambio por favores políticos de allegados al poder (Bayer et al., 2010). En este caso, en una operación novedosa y única en la historia de la formación del patrimonio nacional, el Estado intercambió territorios expoliados a los masacrados indígenas del sur por materiales arqueológicos de los "extintos" indígenas del noroeste. El resultado fue el enriquecimiento de un miembro de la élite tucumana con vínculos con el poder y el crecimiento del patrimonio histórico estatal, ambos pagados con recursos indígenas.

\section{Nuevas incursiones internacionales}

Luego de colaborar con el "notable aumento" de las secciones del Museo Nacional (MJCIP, 1900, p. 575), Zavaleta siguió reuniendo exorbitantes cantidades de material, que orientaría hacia el mercado internacional. Si bien estas ventas no son el centro de este trabajo, no puedes dejar de mencionarse como parte del proceso de incremento -cada vez más aceitado- de su ya consolidado peculio.

Las exposiciones internacionales constituían una plataforma de contacto con el mercado internacional y una estrategia de exhibición del mundo, que naturalizaba la diferencia entre las naciones atrasadas y civilizadas, legitimando el imperialismo (Zusman, 2012). Persiguiendo el propósito de ser parte del segundo grupo, Argentina participaba asiduamente de estas, exponiendo sus recursos naturales, manufacturas y avances científicos. En este contexto, Zavaleta se presentó en la Louisiana Purchase Exposition de1904 (Penhos, 2009; Parezo y Munro, 2010; Gluzman, 2018). Si bien esta última señala que Zavaleta no aparece mencionado como representante oficial del gobierno argentino, distintos diarios americanos destacaron su presencia. Primero, anunciando que el presidente Roosevelt recibiría a ciertas personalidades y delegaciones participantes:

[...] prominent foreigners who were received were José de Olivares, ${ }^{17}$ commissioner from Argentina to the St. Louis Exposition, and Mrs. Olivares; Juan P. Tomas, managing editor of the leading commercial paper of Argentina, and Manuel B. Zavaleta, de foremost archeologist of that republic.("At the White House",1904).

Este lugar privilegiado de Zavaleta se expresó en la exhibición en un pabellón especial, de "one of the most notable and interesting in the world, and has required forty-two large cases for transportation to this country" ("At the White House: Prominent Foreigners Call", 1904). Los periódicos destacaron que los objetos, resultado "of twenty - eight years of research" ("Exhibit of Argentina's prehistoric people", 1904), permitían conocer los hábitos del pueblo calchaquí. W.J. McGee, jefe del Departamento de Antropología, examinó la colección previo a la apertura al público ("Notes of Happenings at the World's fair", 1904) y concretó allí la primera compra de la exposición. Zavaleta recibió el gran premio y una mención honorífica, reconocimientos que agradeció con un discurso sobre su propio esfuerzo, que ganaba historicidad:

Zavaleta, who speaks only Spanish, in referring to his collection, said through his private secretary, Carlos C. Reissig ${ }^{18}$ : "In the many years it has taken me to collect the exhibit I have been subjected to many hardships in my work, and have often times and for weeks at the time lost my way in the mountains of Argentina, and only found it after having the good fortune to meet a party of Traveler" ("Plenty of material now in St. Louis for great Museum of natural history", 1904).

17 Olivares era delegado de la Exposición en Sudamérica, organizador continental y encargado de invitar a los delegados de sección de cada país.

18 Podría tratarse del periodista y escritor argentino Carlos Reissig. 
El diario argentino La Nación, que poco había apoyado el éxito argentino de otras secciones (Penhos, 20009), anunciaba triunfante:

El museo de Chicago ha comprado la colección de antigüedades calchaquíes, de propiedad de D. Manuel B. Zavaleta, que éste exhibía en la exposición de San Luis, y que ha llamado extraordinariamente la impresión de arqueólogos y antropologistas. La colección comprende numerosos objetos de barro cocido, instrumentos de cobre, muchos ídolos admirablemente conservados y una colección de cráneos que, según los especialistas, constituye el principal interés, desde el punto de vista de la antropología sudamericana. El profesor Mc Gee, jefe de la sección de antropología en la exposición, descubrió que la mayor parte de esos cráneos presentaban cicatrices de trepanación, y que uno de ellos revelaba que la operación había sido practicada tres veces con éxito, no obstante los instrumentos rudimentarios empleados en época tan remota. Llenado el objeto de su viaje, el seńor Zavaleta partirá en seguida para Londres y Alemania, y en enero próximo se hallará de vuelta en Buenos Aires (La Nación, 1904).

La colección de Chicago constó de 4565 piezas: 271 fueron catalogadas como parte de la Colección Peruana; de las restantes, solo 400 se catalogaron y el resto fueron numeradas (Field Museum, 1919). El precio se mantuvo en silencio, generando distintas especulaciones: se decía que rondaba los 100000 dólares ("Chicago gets rare relics", 1904). La correspondencia de Karl von den Steinen, director del Museum für Völkerkunde de Berlin, transcripta por Farro, permite ver cómo Franz Boas le planteaba sus dudas al respecto: "I am interested to know whether you meant to say $\$ 17.000$ or $\$ 117.000$. Your letter has \$ 117.000" (Boas, 1904). En posteriores cartas se indica que se pagaron 17000 dólares (39 950 pesos moneda nacional), precio que fue tomado como base en 1906 para la compra de 5740 piezas de la "vieja región diaguita calchaquî" (Debenedetti, s.f. $)^{19}$ por el Museo de Berlín. Esta negociación

19 Los objetos corresponden a Salta: Rancagua (Cachi) fue ardua; Von den Steinen comunicó a Zavaleta que lamentaba ofrecer una suma escasa respecto al trabajo y riesgos corridos, pero que no era posible tomar como referencia sus ventas anteriores por la "vulgarización" de lo calchaquí, debida a la proliferación de colecciones similares. Además, si bien la colección tenía cuatro veces más urnas, también tenía cuatro veces más calaveras, de "poco valor". Finalmente, se pagaron 110000 marcos (26.190 dólares) en carácter "compensatorio" por el esfuerzo y los traslados. Años después, la colección fue estudiada por Eric Boman, quien hizo anotaciones en los catálogos (González, 1983) y por Salvador Debenedetti, cuyas notas, sumamente críticas, denuncian la falta de criterio de la colección y la ausencia de datos de procedencia, que considera "más importantes que el objeto mismo" (Debenedetti, s.f.).

\section{La última venta al Museo Nacional}

La “devaluación” de las colecciones calchaquíes apreciada por Von den Steinen se potenció en Buenos Aires. Farro (2008) la explica a partir de la "doctrina de la escasez" acuñada por Penny para el mercado internacional de antigüedades a fines del XIX. $\mathrm{El}$ argumento es adecuado en cuanto al punto de vista cuantitativo; pero a esto debe sumarse el problema de las implicancias sociales de los criterios de valor. He planteado (Tolosa, 2018) que el prestigio de este tipo de bienes se definió a partir de un complejo simbólico que incluyó criterios de unicidad, originalidad, antigüedad y autenticidad, base de su definición como piezas valiosas y museificables (Maquet, 1999) que en un contexto de mayor oferta se ven afectados, impactando en su significación y usos sociales.

En el Museo Nacional, los ingresos de esa zona seguían multiplicándose. En febrero de1890, Burmeister regresaba de Salta con seis cajones con cueros, insectos y 149 objetos arqueológicos, cráneos

Santa Rosa (San Carlos) Patr. [sic] Grande (La Poma) Angostura (San Carlos) Cachi, La Paya, Payogasta, Tacuil (Molinos), Palermo (Cachi), Cafayate, San Isidro (Cafayate) Tolombon, La Poma, Luracatao (Molinos) Angastaco (San Carlos). Catamarca: Fuerte Quemado (Santa Maria), Andalgalá, Choya (Andalgalá), cerro Colorado (Londres) Belén. Tucumán: Quilmes (Tafí) El Paso (Amaicha) San Javier. 
y quijadas (Expedición científica, 1890). En 1903 ingresó una colección

[...] de antigüedades calchaquíes procedentes del sepulcro de La Paya en el Noroeste de la Provincia de Salta, adquirida por el Superior Gobierno de los señores Martínez y González de aquella región, ${ }^{20}$ consistente en una diadema luminar de oro con accesorios del mismo metal, de un hacha de bronce con mango de madera, una manopla de adoración, cinceles, cuchillos, y varios objetos de madera y de alfarerías (MJCIP, 1903, p. 369).

Los posteriores trabajos de Ambrosetti en La Paya devinieron en 174 piezas; él donó además veinte objetos de bronce: brazaletes, hachas, agujas, placas, pectorales, discos. Se obtuvieron por canje dos adornos frontales de plata y de oro; un mortero de piedra de Catamarca y Rodolfo Lemos de Calingasta donó una momia (MJCIP, 1906, pp. 17-18). Esta constante incorporación demuestra la poca necesidad de seguir comprando colecciones calchaquíes, sobre todo cuando el museo continuaba sin edificio.

No obstante, en 1907 Zavaleta volvió a la carga con lo que parecía ser su mayor logro en términos cuantitativos: una colección de 11590 piezas "con un libro" (Zavaleta, 1906) que contenía el catálogo ${ }^{21}$ de la colección, fotografías de algunos objetos y de las campańas. La propuesta fue tratada el 5 de junio en Comisión de Peticiones de Diputados. Zavaleta pidió que se calculara el monto tomando como base el de 1899 pero considerando que ahora se ofrecían 9581 piezas más, y que se repitiera el pago con tierras fiscales. De haberse dado curso a ese pedido, se habrían superado los 288000 pesos.

La comisión convocó a Ameghino, que en ese momento dirigía el Museo Nacional. Esta vez, su

20 No he encontrado otros datos sobre esta compra oficial.

21 La publicación es copia textual de un manuscrito existente en el Archivo Fotográfico y Documental del Museo Etnográfico J. B. Ambrosetti, procedente del Museo Nacional. Los objetos están numerados del 1 al 11590. A la derecha aparece, con tinta azul, con una numeración posterior, que va desde el 906/1194 (objeto 1) hasta el 906/6257 (objeto 5060). veredicto no fue positivo. Indicó que conocía la colección "de un modo muy imperfecto," que el catálogo resultaba insuficiente para emitir un juicio y que el valor pecuniario de la colección no podía establecerse por comparación con colecciones anteriores. Fríamente, señalaba que "el propietario"

\section{[...] hace resaltar que el Honorable Con-} greso le compró, por la cantidad de 50.000 pesos moneda nacional, una colección que constaba tan sólo de dos mil nueve piezas, mientras que la colección actual consta de once mil quinientos noventa ejemplares. Sin embargo, no es por el número de ejemplares que debe juzgarse del valor de la colección sino por la calidad de las piezas y otras múltiples circunstancias que sería demasiado largo enumerar. Así es que, según el Catálogo, entre los 11.590 objetos, más de 6.000 son puntas de flecha en piedra cuyo valor es casi nulo; encontrándose en el mismo caso muchas otras piezas (Ameghino, 1907).

Ameghino coincidía sobre la disminución del valor de los objetos calchaquíes en las últimas décadas, por estar los museos "atestados de objetos parecidos”. Esto echaba por tierra la base de negociación cantidad/precio que Zavaleta intentaba sostener. En este sentido, la depreciación operada sobre estos objetos (Tabla 2), confirma cómo el valor de cambio pareció regirse por reglas de mercado, tal como han señalado Lenton (2005) y Farro (2008).

Pese a la reticencia de Ameghino, la comisión (diputados Berrondo, Martínez y Gutiérrez) elevó un proyecto copiado textualmente del de 1899 , aceptando la venta en "[etrarenta] 35 mil pesos moneda nacional, pagaderos en tierras públicas" $(\mathrm{CN}$, 1907 a, p. 886, tachado en el original). El 11 de septiembre, el diputado Delcasse mocionó la urgencia de tratarlo antes del fin de sesiones y no postergarlo al año siguiente (CN, 1907a, pp. 995-996). Con notable premura, fue debatido quince días después.

El miembro informante alegó las fórmulas ya conocidas sobre la importancia científica de la colección, el inconmensurable esfuerzo de Zavaleta y una serie de informaciones plagadas de inexactitudes, no solo 
Tabla 2. Cuadro comparativo del promedio de venta por pieza en las diferentes ventas de Zavaleta.

\begin{tabular}{|c|c|c|c|c|}
\hline Venta & Institución & $\mathrm{N}^{\circ}$ objetos & Precio total & $\begin{array}{c}\text { Promedio } x \\
\text { unidad }\end{array}$ \\
\hline 1885 & Museo Nacional & 105 & $\$ \mathrm{~m} / \mathrm{n} 5000$ & $\$ \mathrm{~m} / \mathrm{n} 47,62$ \\
\hline 1887 & Museo Nacional & 275 & $\$$ oro $10000(\$ \mathrm{~m} / \mathrm{n} 13500)$ & $\$ \mathrm{~m} / \mathrm{n} 49,09$ \\
\hline 1888 & Museo de La Plata & 400 & $\$ \mathrm{~m} / \mathrm{n} 16500$ & $\$ \mathrm{~m} / \mathrm{n} 41,25$ \\
\hline 1899 & Museo Nacional & 2009 & $\begin{array}{l}\$ \mathrm{~m} / \mathrm{n} 50000 \text { (oficial) } \\
+\$ \mathrm{~m} / \mathrm{n} 78309 \text { (reales) }\end{array}$ & $\begin{array}{l}\$ \mathrm{~m} / \mathrm{n} 24,88 \\
\$ \mathrm{~m} / \mathrm{n} 38,97\end{array}$ \\
\hline 1904 & Chicago Field Museum & 4565 & $\begin{array}{c}\text { US\$ } 17000 \\
\text { (aprox. \$ m/n } 39950 \text { ) }\end{array}$ & $\begin{array}{c}\text { US\$ } 3,72 \\
(\$ \mathrm{~m} / \mathrm{n} 8,75)\end{array}$ \\
\hline 1906 & Berlín & 5740 & $\begin{array}{l}\text { Marcos } 110000 \\
\text { (aprox. US\$27000 ó } \\
\$ \mathrm{~m} / \mathrm{n} 61456 \text { ) }\end{array}$ & $\begin{array}{l}\text { Marcos 19,16 } \\
(\$ \mathrm{~m} / \mathrm{n} 10,70)\end{array}$ \\
\hline $5^{\circ} .1907$ & Museo Nacional & 11.590 & $\$ \mathrm{~m} / \mathrm{n} 35000$ & $\$ \mathrm{~m} / \mathrm{n} 3,02$ \\
\hline
\end{tabular}

en cuanto a fechas y a número de piezas, sino sobre los informes del ministro de Instrucción y de Ameghino. Destacó que la colección era necesaria para el país, ya que "aquella que había presentado el señor Zabaleta había sido distribuida en distintos museos y que por lo tanto no existe entre nosotros una colección completa de este género" (CN, 1907a, p. 995). El apresuramiento, los errores y omisiones, la modificación de informes y la copia textual del proyecto anterior son notorios, pero es difícil determinar si respondían a la negligencia de la comisión o esta simplemente reproducía el discurso del interesado. No obstante, esta vez el pago en tierras fue objetado. El diputado Méndez Casariego enunciaba:

[S]e ha sostenido en varias ocasiones que la tierra no desempeña rol de moneda. Si esa colección vale 35.000 pesos, que se pague en dinero, pero no en tierras. No es este el único asunto que se ha traído á la consideración de la honorable cámara en que se ha fijado la tierra como instrumento de remuneración, ya sean primas á ferrocarriles, ó compensaciones de otra naturaleza, pero se ha aceptado este criterio: que no se debe pagar con tierras, sino con dinero (CN, 1907a, 1275).

El diputado Luro agregaba que "las cosas valen en el instrumento de apreciación que todo el mundo conoce. Si esta colección vale 35000 pesos, debe pagarse en dinero" (CN, 1907a, 1275). Estas objeciones determinaron el pago en pesos. La época de abundancia en que la tierra se repartía como moneda en el círculo cercano al poder estaba finalizando.

El 23 de septiembre se sancionó la Ley 5.230. En su discurso, el senador Del Pino mencionó nuevamente los "informes muy satisfactorios de Europa", la reciente adquisición de Berlín e informó que Zavaleta aceptaría el pago que se definiera, aunque no le fuese conveniente:

He tenido ocasión de hablar personalmente con el interesado, persona seria, que denota en su trato una inteligencia vivaz. Hombre de actividad, de trabajo persistente, así como de una sinceridad y honestidad que fácilmente se descubre en él, díjome que con 35.000 pesos apenas podría cubrir, parte de los gastos que le ha costado reunir esa colección que ofrece; y, efectivamente, así debe ser, desde que basta considerar que la región calchaquí es extensa, escabrosa, difícil de recorrer, muy lejana de las líneas férreas, y si se tiene en cuenta que el personal que ha tenido que ocupar debe haber sido numeroso, y crecido el gasto que ha debido hacer principalmente para efectuar las excavaciones, para desenterrar viejos y numerosos objetos $(\mathrm{CN}$, 1907b, p. 1027). 
El destructor de huacas. La acción de Manuel B. Zavaleta en la constitución del "patrimonio arqueológico” calchaquí...

Tabla 3. Total de las ventas, expresadas en moneda nacional.

\begin{tabular}{|c|c|c|}
\hline $\begin{array}{c}\text { Total objetos vendidos } \\
\text { por Zavaleta } \\
\text { y sus pagos }\end{array}$ & 24684 objetos & $\begin{array}{c}70000 \$ \mathrm{~m} / \mathrm{n} \\
61209 \text { ha en Pampa } \\
\text { +arriendos }=(+78309 \$ \mathrm{~m} / \mathrm{n}) \\
17000 \text { dólares } \\
110000 \text { marcos }\end{array}$ \\
\hline \multicolumn{2}{|c|}{ Total pagado, en $\$ \mathrm{~m} / \mathrm{n}$} & $\$ \mathrm{~m} / \mathrm{n} 249715$ \\
\hline
\end{tabular}

La cita explicita la gestión personal de Zavaleta con agentes claves para sus operaciones, más allá de sus contactos parentales. En este sentido, es interesante destacar cómo la construcción de autonomía de Zavaleta respecto del campo científico se sustentó en el armado de relaciones políticas que, si bien lo excluyeron de dicho campo, fueron mucho más rentables y presentaban menos oposición a sus intereses. El sector político no poseía conocimientos para evaluar el material, no opinaba sobre su metodología, alababa sus prácticas y modificaba convenientemente la opinión de los científicos, que solo ocupaban un rol formal. Además, como estos declinaban la responsabilidad de poner precio a las colecciones, esa resolución (la más importante para Zavaleta) quedaba en manos de los políticos. Así, el ámbito legislativo fue sumamente beneficioso para el huaquero devenido en ejemplo de la arqueología nacional. Su capacidad de gestionar relaciones, sustentada en su pertenencia a la élite tucumana y a su capital de relaciones familiares, le permitió trascender su provincia y orientarse -en el extranjero y en Buenos Aires- hacia sujetos convenientemente posicionados que permitieron el éxito de sus negocios, cuyas ganancias podrían sintetizarse como se indica en la Tabla 3.

En 1947, las colecciones arqueológicas del Museo Nacional (ahora Museo de Ciencias Naturales "Bernardino Rivadavia") fueron transferidas al Museo Etnográfico de la Universidad de Buenos Aires, por Decreto 16.211. La nota de traspaso aporta datos sobre el ingreso de 1899 y el registro de la colección, donde "se puede apreciar las piezas faltantes a la fecha" ("Nota de traspaso de la colección”, 1947). ${ }^{22}$ El Libro de Inventario del Museo Nacional guarda también información de la primera colección, pero

22 En la numeración de 1947, las 2009 piezas de 1899 van del 1594 al 3603. no hay registro de la de 1887. En el Museo Etnográfico existe también la libreta autógrafa de Zavaleta (original del libro de 1906) con las 11.590 piezas vendidas en 1907. Curiosamente, en el último folio de ese legajo aparece una nota sin firma de 1978 que hace referencia a una cuarta colección que, según la planilla anexada al Expediente UBA N ${ }^{\circ} 17905 / 46$, "fue adquirida al Sr. D. Manuel B. Zavaleta el año 1906” e ingresó al Museo Etnográfico con la transferencia de 1947, pero "nunca tuvo entrada en los registros de los museos citados. Por el registro particular de esta colección, que obra en el presente legajo, se pueden apreciar las piezas existentes y las faltantes al día de la fecha” (Nota del 14 de febrero de 1978). No he encontrado datos que permitan precisar si se trata de un error de fechado o realmente se compró otra colección ese año. Una carta de Ameghino al ministro Rómulo Naón en 1910 señala el comienzo de "la demolición del piso alto del Colegio Nacional, central donde se hallan el taller de moldear y la gran colección de Arqueología comprada por el Superior Gobierno al Sr. Manuel Zavaleta" (Ameghino, 1910). ¿Incluiría dicha colección piezas de esta venta de 1906 ?

\section{Palabras finales}

Lo analizado permite considerar que la acción de Zavaleta, depredadora en lo que al material arqueológico se refiere, fue exitosa desde el punto de vista comercial. Su estrategia, centrada en una publicidad propia sobre su trabajo, pudo ponerse en práctica gracias a las relaciones establecidas con actores de diferentes niveles institucionales, posibilitadas por la formacion, competencias y capital social propios de su posicion en la élite tucumana.

He planteado que la responsabilidad asignada enteramente a Zavaleta -cuya escala de la acción permitió 
constituirlo cómodamente como el enemigo principal de la integridad de sitios y materiales arqueológicos- ha invisibilizado la de otras agencias intervinientes en la comercialización de antiguedades. Respecto del círculo científico, hemos visto que el inicial apoyo terminó en fuertes críticas por la desprolijiad de sus entregas y por la definición de pautas de método y registro que alejaron la ciencia arqueológica del primer coleccionismo. Sin embargo, aunque discursivamente la diferenciación fue muy explítica, los arqueólogos participaron activamente en la dinámica de ese mercado, sosteniendo las prácticas de compra de piezas, modificando la demanda e incidiendo en la fluctuación de precios. En realidad, el discurso científico no produjo una reflexión honesta sobre su propio rol como motor impulsor del crecimiento del huaqueo y del comercio de antigüedades (Tolosa, 2018 y en prensa).

Zavaleta tuvo consciencia de su rápido desprestigio en el campo científico (el que utilizó cuando le resultó conveniente) y se abocó a solidificar las vinculaciones con el sector político, más redituables y menos conflictivas. No obstante, se siguió presentando como una figura de la arqueología argentina, aun cuando ese campo lo rechazaba. En este sentido, su estrategia discursiva fue resultado del entrecruzamiento de discursos y opiniones favorables, evitando las detractoras y utilizando intersticios de no-comunicación entre los ámbitos científicos (nacional y extranjero) y el político.

En dicha estrategia también es posible reconocer la repetición de ciertos tópicos. Por ejemplo, el esfuerzo del trabajo y los viajes, fórmula asociada tanto con una construcción heroica y vocacional como con un parámetro de pago. Esto es especialmente visible en el contexto de depreciación de los objetos calchaquíes, donde se evaluaba "el número relativamente considerable de objetos de barro y de piedra, cuya recolección y transporte ha exigido indudablemente la inversión de sumas bastante elevadas" $(\mathrm{CN}, 1907 \mathrm{c})$, planteándose un pago "compensatorio" por esto. En este punto he destacado que además del señalado impacto negativo del exceso de oferta sobre el precio de las piezas, debe considerarse que la "masificación" atentó contra el valor social de prestigio de estos objetos y su consumo. Esto permite explicar su progresiva categorización cercana al concepto de "mercancías" simples, tal como se observa en su valoración basada en los "costos" de producción (en este caso el trabajo social invertido en su excavación, limpieza, transporte $)^{23}$ que se impuso sobre los anteriores mecanismos de prestigio y discriminación propios del sistema de valores sociales de la época (Baudrillard, 2011). La estrategia de Zavaleta incorporó recursos como la publicación de un libro y el uso de fotografías, lo que le permitió poner en imagen no solo la colección como resultado sino también mostrar el paisaje de origen de las piezas y el proceso de trabajo en el campo, con su propio protagonismo junto a los peones (Figura 1), aspectos que sustentaban el discurso sobre el esfuerzo y la dedicación sostenidos durante su carrera.

Por último, he destacado el rol central del Estado en estos episodios de patrimonialización, opacado tras un protagonismo adjudicado casi exclusivamente a Zavaleta. La revisión de las fuentes permite plantear la responsabilidad estatal en las negociaciones. En primer lugar, como comprador a gran escala, explícito formador de precios y legitimador de prácticas que eran ya observadas negativamente por los científicos. Luego, por la gran contradicción entre la erogación para comprar colecciones y la falta de inversión en infraestructura de los museos, lo que indica que el problema no era la carencia de dinero sino a dónde se dirigía. Por último, por el carácter confuso de las negociaciones, especialmente la de 1899 , que muestra diferencias sustanciales entre lo legislado y la concreción del pago. Este caso, paradigmático en la historia patrimonial, ejemplifica especialmente la política y mecanismos acumulativos del Estado sobre los medios de producción y reproducción indígenas (económicos o culturales) en su propio beneficio.

23 Este análisis podría completarse si existieran datos que permitieran calcular la plusvalía extraída por Zavaleta del trabajo de sus peones, que las fotografías publicadas en 1906 muestran en número de cinco a doce personas. Por otro lado, los costos de transporte debían ser cuantiosos, ya que las piezas se trasladaban desde diferentes puntos del valle a Tafí, en canastos a lomo de mula. Allí se encajonaban con lana para amortiguar y seguían en mula hasta el ferrocarril; desde ahí a Buenos Aires y luego en barco a destinos internacionales. Los gastos incluían el material para encajonar, las mulas, su pastura, peones para guiarlas y descargar cajones, pasajes, etcétera. Como referencia de la cantidad de cajones, para la colección de 1887 eran 20, y 48 para la de Saint Louis. 


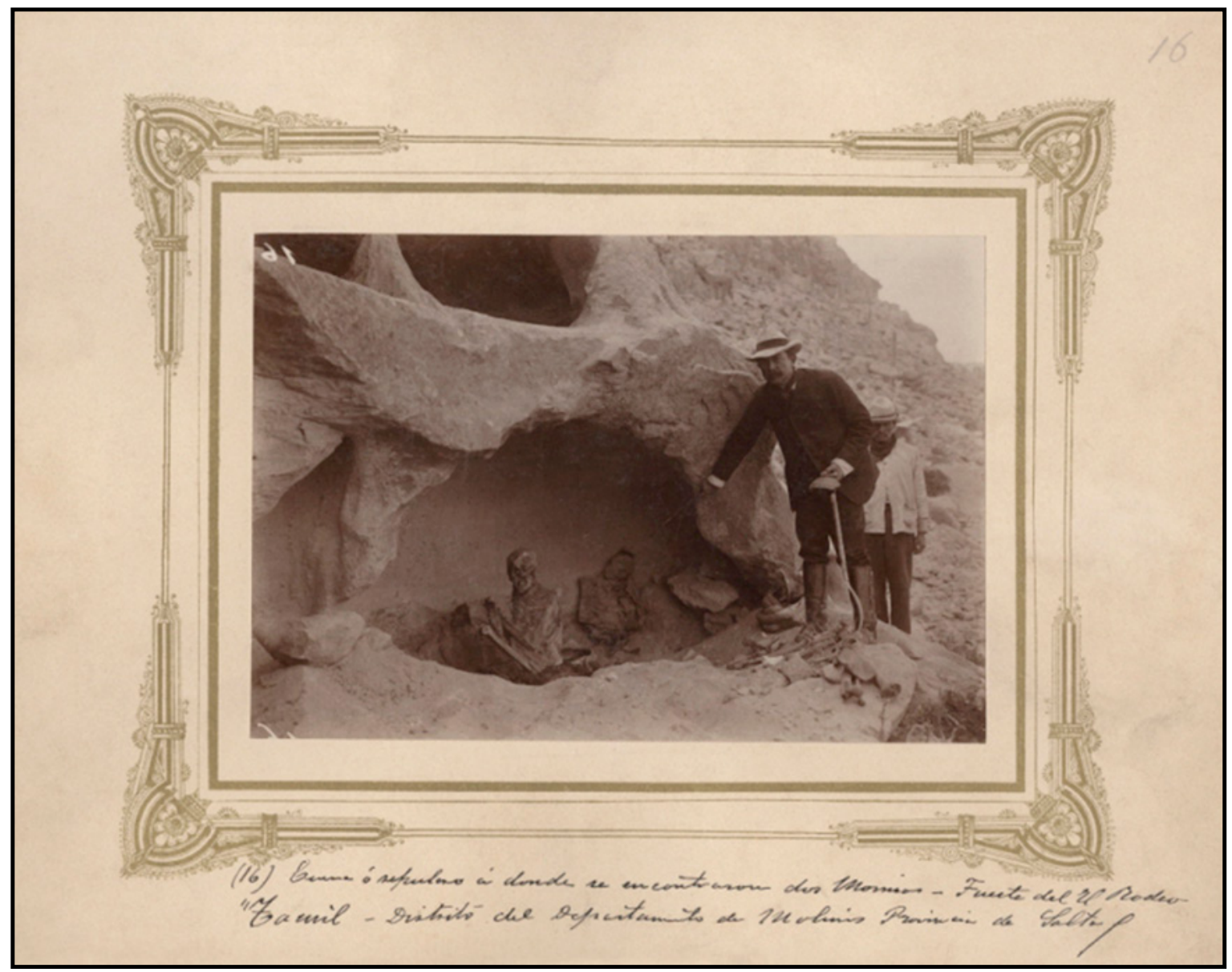

Figura 1. Fotografía de Zavaleta mostrando una tumba en Molinos.

Fuente: Manuel Zavaleta, Zwei Mumien, Ident. VIII E1761. Ethnologisches Museum, Staatliche Museen zu Berlin.

De este modo, el accionar individual de Zavaleta debe ser puesto en contexto para dimensionar su verdadera profundidad, ya que su actividad fue posible por la existencia de un entramado de responsabilidades compartidas. Pronto, la creciente tensión entre una desmedida y poco planificada acumulación de materiales, una despareja conciencia estatal sobre la patrimonialización, la falta de un proyecto de política cultural estatal y las limitaciones metodológicas señaladas pusieron en crisis el modelo de formación de colecciones del siglo XIX. Como hemos mencionado, en la primera década del siglo XX, el Estado legislaría su primera ley de propiedad sobre el patrimonio y definiría los actores autorizados para su manejo. Luego de desarrollarse sin restricciones, la etapa de acumulación primitiva de materiales para museos llegaría, al menos formalmente, a su fin.
Este trabajo surge de la investigación para mi tesis doctoral Los Antiguos y el estado. Historia de la construcción material del patrimonio arqueológico, sur de los valles Calchaquies (1877-2008) defendida en 2018 en la Facultad de Filosofía y Letras, Universidad de Buenos Aires.

\section{Referencias citadas}

Academia Argentina de Letras (1942). Diccionario de americanismos. Boletín de la Academia Argentina de Letras. Tomo X (40), 789-896.

Ambrosetti, J. B. (1897). La antigua ciudad de Quilmes (Valle Calchaquí). Boletín del Instituto Geográfico Argentino, 18, 33-70. 
Ambrosetti, J. B. (1907). Exploraciones arqueológicas en la ciudad prehistórica de "La Paya". Valle Calchaqui, Provincia de Salta. Campañas de 1906 y 1907. Buenos Aires: Biedma.

Ameghino, F. (1878). Catálogo especial de la sección antropológica y paleontológica de la República Argentina en la exposición Universal de París de 1878. En Torcelli, A. (1914). Obras completas y Correspondencia Cientifica de Florentino Ameghino. Tomo II (pp. 241-327). La Plata: Taller de Impresiones oficiales.

Ameghino, F. (1885). Carta a Zavaleta, enero de 1885. En Torcelli, A. (1914). Obras completas y Correspondencia Cientifica de Florentino Ameghino. Tomo XX, Carta 327 (p. 309). La Plata: Taller de Impresiones Oficiales.

Ameghino, F. (1888a). Carta a Zavaleta, 20 de julio de 1888. En Torcelli, A. (1914). Obras completas y Correspondencia Cientifica de Florentino Ameghino, Tomo XX, Carta 537 (p. 472). La Plata: Taller de Impresiones Oficiales.

Ameghino, F. (1889). Carta a Zavaleta, 26 de junio de 1889. En Torcelli, A. (1914). Obras completas y Correspondencia Cientifica de Florentino Ameghino, Tomo XIX (pp. 10111015). La Plata: Taller de Impresiones Oficiales.

Ameghino, F. (1891). Sobre algunos restos de mamíferos fósiles, recogidos por el Señor Manuel B. Zavaleta en la formación miocénica de Tucumán y Catamarca. Revista Argentina de Historia Natural, I, 88-101.

Ameghino, F. (1907). Informe a la Comisión de Peticiones de la Cámara de Diputados de la Nación Argentina. (3 de julio de 1907). Archivo del Congreso de la Nación Expediente 81-P-1907, procedencia: Particulares; Comisión Cabecera: Peticiones y Poderes., Caja 1, Orden del día 32. http://apym.hcdn.gob.ar/pdf/expedientes/81-p-1907. pdf.

Ameghino, F. (1910). Carta al ministro Rómulo Naón, s.f. En Torcelli, A. (1936). Obras completas y Correspondencia Científica de Florentino Ameghino. Tomo XIX, Carta 2608. La Plata: Taller de Impresiones Oficiales.

Ametrano, S., Podgorny, I. y Lopes, M. M. (2012). Buenos Aires, 1884. De cómo la fragilidad de unos esqueletos derrumbaron el proyecto de un Gran Museo Nacional. Revista Museo Argentino Ciencias Naturales, 14(2), 167-174.
At the White House (1904, June 26). New York Daily Tribune. Chronicling America: Historic American Newspapers, p. 8. Library of Congress. https://chroniclingamerica.loc. gov/lccn/sn83030214/1904-06-26/ed-1/seq-8/

At the White House: Prominent Foreigners Call (1904, June 25). The Evening Star. Chronicling America: Historic American Newspapers, p. 1. Library of Congress. https:// chroniclingamerica.loc.gov/lccn/sn83045462/1904-0625/ed-1/seq-1/

Baudrillard, J. (2011). Critica de la economia politica del signo. Buenos Aires: Siglo XXI.

Bayer, O. (Coord.) y Lenton, D. (Ed.) (2010). Historia de la crueldad argentina. Julio A. Roca y el genocidio de los Pueblos Originarios. Buenos Aires: El Tugurio.

Boas, F. (1904). Carta a Karl von den Steinen, 23 de diciembre de 1904. En Farro, M. (2008). Historia de las colecciones en el Museo de La Plata, 1884-1906: naturalistas viajeros, coleccionistas y comerciantes de objetos e historia natural a fines del Siglo XIX (Tesis doctoral). Facultad de Ciencias Naturales y Museo, Universidad de La Plata, Apéndice IV-VI. Argentina.

Bottini Ángel Compra Fábrica E Hipoteca A Zavaleta Manuel B. (1895) [Escritura 1960] Archivo Histórico de Tucumán, Serie A, Vol. 119, 1895. San Miguel de Tucumán.

Burmeister, H. (1885, febrero 23). Informe del doctor Burmeister sobre una colección. El Orden, p. 1. Hemeroteca del Archivo Histórico de Tucumán. San Miguel de Tucumán, Argentina.

Carro, J. A. (1894). Carta a Lafone Quevedo, 5 de octubre de 1894. En Farro, M. (2008). Historia de las colecciones en el Museo de La Plata, 1884-1906: naturalistas viajeros, coleccionistas y comerciantes de objetos e historia natural a fines del Siglo XIX (Tesis doctoral). Facultad de Ciencias Naturales y Museo, Universidad de La Plata. Argentina.

Chicago gets rare relics (1904, November 24). The NewsHerald, Hillsboro. Chronicling America: Historic American Newspapers, p. 6. Library of Congress. https:// chroniclingamerica.loc.gov/lccn/sn85038161/1904-1124/ed-1/seq-6/

Colecciones científicas (1885, enero 21). El Orden, p. 1. Hemeroteca del Archivo Histórico de Tucumán. San Miguel de Tucumán, Argentina. 
El destructor de huacas. La acción de Manuel B. Zavaleta en la constitución del "patrimonio arqueológico” calchaquí...

Congreso de la Nación [CN] (1899). "Estableciendo la compra de la colección de antigüedades calchaquíes pertenecientes a Manuel B. Zavaleta. Archivo del Congreso de la Nación Argentina, Expediente 38-S-1899”. Ingreso enero de 1899. Procedencia Senadores, Comisión Cabecera Cultura, Caja 73, 11 pp. Ciudad Autónoma de Buenos Aires.

CN (1896a). Acta de Sesiones Ordinarias 17 de junio de 1896, Libro 34, $\mathrm{N}^{\circ}$ 14. http://www.archivolegislativo. com.ar:8080/gsdl/collect/incunabl/actas/18960617.html

CN (1896b). Acta de Sesiones Ordinarias, 8 de julio de 1896, Libro 34, $\mathrm{N}^{\circ}$ 20. http://www.archivolegislativo.com. ar:8080/gsdl/collect/incunabl/docs/18960708.pdf

CN (1899). Diario de Sesiones de la Cámara de Diputados. Sesiones Ordinarias. Buenos Aires: Imprenta Mariano Moreno.

CN (1900). Diario de Sesiones de la Cámara de Senadores periodo 1899. Buenos Aires: Imprenta Mariano Moreno.

CN (1907a). Diario de Sesiones de la Cámara de Diputados. Sesiones Ordinaria, abril 29-septiembre 30. Buenos Aires: Establecimiento Linotipográfico "La Patria degli Italiani”.

CN (1907b). Diario de Sesiones de la Cámara de Senadores del año 1907. Tomo I, Sesiones Ordinarias. Buenos Aires: Establecimiento Tipográfico "El Comercio".

CN (1907c). Expediente 81-P-1907. Procedencia: Particulares; Comisión Cabecera: Peticiones y Poderes. Archivo del Congreso de la Nación, Caja 1, Orden del día 32. http://apym.hcdn.gob.ar/pdf/expedientes/81-p-1907. pdf.

Córdova, F. y Camusso, J. (1922). Mapa Catastral Orohidrográfico del Territorio de La Pampa con sus vías de comunicación y división territorial. En http://norbertomollo.blogspot.com/2012/11/mapas-y-planos-antiguosde-la-pampa.html

Debenedetti, S. (s.f.). Notas sobre la colección Zavaleta, depositada en Dahlem. Archivo Fotográfico y Documental del Museo Etnográfico Juan Bautista Ambrosetti, Fondo de Gestión Institucional Académico-Administrativa Institucional, Serie Historia de las Colecciones, Legajo Zavaleta, Carpeta 1, F:3. Ciudad Autónoma de Buenos Aires.
De La Vaulx, H. (1901). Excursion dans les vallées Calchaquies (province de Tucuman). Poteries indigènes. Journal de la Société des Américanistes, 3(2), 168-176.

Exhibit of Argentina's prehistoric people (1904, June 26). The Washington Times. Chronicling America: Historic American Newspapers, p. 12. Library of Congress. https:// chroniclingamerica.loc.gov/lccn/sn84026749/1904-0626/ed-1/seq-12/

Expedición Cientifica (Febrero de 1890) Carlos V. Burmeister a Provincia de Salta (Quebrada del Toro Ingaguasi y Seclantás). Archivo Fotográfico y Documental del Museo Etnográfico Juan Bautista Ambrosetti, Fondo Salvador Debenedetti. Ciudad Autónoma de Buenos Aires.

Farro, M. (2008). Historia de las colecciones en el Museo de La Plata, 1884-1906: naturalistas viajeros, coleccionistas y comerciantes de objetos e historia natural a fines del Siglo XIX (Tesis doctoral). Facultad de Ciencias Naturales y Museo, Universidad de La Plata. Argentina.

Field Museum of Natural History (1919). Annual Report of the Director to the Borad of Trustees for the year 1918. Report Series, 5(4). Chicago, USA.

Giudicelli, C. (2011). Lectura de las ruinas. La fabricación de antepasados aceptables en el noroeste argentino ( $\mathrm{Si}$ glos XVI-XVII/siglo XIX). En Bernabéu A., S. y Langue, F. Fronteras de las sensibilidades (pp. 125-150). Madrid: Doce Calles.

Gluzman, G. (2018). La colección Zavaleta y su traslado al Field Museum de Chicago: aproximación desde la vida social de los objetos. Arqueología, 24(2), 67-86.

González, A. R. (1983). Notas sobre religión y culto en el Noroeste argentino prehispánico. A propósito de unas figuras antropomórficas del Museo de Berlín. BresslerArchiv, Neue Folge, Band XXXI, 219-281.

Groussac, P., Bousquet, A., Liberani, I., Terán, J. M. y Frías, J. (1882). Primera Memoria histórica y descriptiva de la Provincia de Tucumán. Buenos Aires: Imprenta M. Biedma.

Guilaine, L. (1896, septiembre 30) "Antiquités calchaquíes". Les Temps, p. 3.

Herrera, C. (2006). La élite tucumana: familias, azúcar y poder. La Generación del Centenario y su proyección en el 
Noroeste Argentino, 1900-1950. Tucumán, Argentina: CC Alberto Rougés.

Lafone Quevedo, S. (1897, febrero 27). "Bric à brac y arqueología”. La Nación, p. 4.

La Nación (1904, noviembre 17), p. 3.

Landrin, F. (1897). Les populations primitives de la République Argentine I y II. En La Nature, Revues des Sciences et de leurs applications aux arts et à l'industrie. Premier semestre, 231-235.

Leguizamón, J. M. (1876a). Remesa de objetos pertenecientes a los Indios Calchaquíes (1876, marzo19). Anales de la Sociedad Cientifica Argentina, II(5), 239-240.

Leguizamón, J. M. (1876b). Viaje al Pucará. Carta a Francisco P. Moreno, Salta, 24.05.1875. Anales de la Sociedad Cientifica Argentina, I(5), 266-272.

Leguizamón, J. M. (1876d). Remesa de objetos pertenecientes a los Indios Calchaquíes. 19 de marzo de 1876. Anales de la SCA, II(5), 239-240.

Lenton, D. (2005). De Centauros a protegidos. La construcción del sujeto de la politica indigenista, desde los debates parlamentarios (1880-1970) (Tesis doctoral en Antropología Social). Facultad de Filosofía y Letras, Universidad de Buenos Aires. Corpus - Archivos virtuales de la alteridad americana 4(2). https://journals.openedition.org/ corpusarchivos/1290

Liberani, I. y Hernández, J. R. (1950) [1877]). Excursión arqueológica en los valles de Santa María, Catamarca, 1877. Tucumán, Argentina: Universidad Nacional de Tucumán.

Libro de Inventario del Museo Nacional (entrada del 31 de agosto de 1887). Archivo Fotográfico y Documental del Museo Etnográfico Juan Bautista Ambrosetti, Fondo de Gestión Institucional Académico-Administrativa Institucional, Serie Historia de las Colecciones, Legajo Zavaleta. Ciudad Autónoma de Buenos Aires.

Lopes, M. M. (2000). Nobles rivales: estudios comparados entre el Museo Nacional de Rio de Janeiro y el Museo Público de Buenos Aires. En Montserrat, M. (Comp.). La ciencia en la Argentina entre siglos. Textos, contextos $e$ instituciones (pp. 277-296). Buenos Aires: Manantial.
Lucas Zavaleta asume el cargo de comisario (1880, febrero 18). Archivo Histórico de Tucumán, Sección Administrativa, 142, Tomo I, f. 208, San Miguel de Tucumán, Argentina.

Maquet, J. (1999) [1972]). La experiencia estética. Madrid: Celeste Editores.

Ministerio de Justicia, Culto e Instrucción Pública [MJCIP] (1885). Memoria presentada al Congreso Nacional de 1886 por el Ministro de Justicia, Culto e Instrucción pública Dr. D. Eduardo Wilde. Buenos Aires: Taller Tipográfico de la Penitenciaría.

MJCIP (1887). Memoria presentada al Congreso Nacional de 1887 por el Ministro de Justicia, Culto e Instrucción pública Dr. D. Filemón Posse. Tomo I - Texto. Buenos Aires: Taller Tipográfico de la Penitenciaría.

MJCIP (1888). Memoria presentada al Congreso Nacional de 1888 por el Ministro de Justicia, Culto e Instrucción pública Dr. D. Filemón Posse. Tomo I - Texto y Anexos de Justicia y Culto. Buenos Aires: Taller Tipográfico de la Penitenciaría.

MJCIP (1893). Memoria presentada al Congreso Nacional de 1893 por el Ministro de Justicia, Culto e Instrucción pública Dr. D. Enrique S. Quintana. Tomo III - Anexos de Instrucción Pública. Buenos Aires: Taller Tipográfico de la Penitenciaría.

MJCIP (1894). Memoria presentada al Congreso Nacional de 1894 por el Ministro de Justicia, Culto e Instrucción pública Dr. D. José V. Zapata. Tomo I - Anexos de Instrucción Pública. Buenos Aires: Compañía Sudamericana de Billetes.

MJCIP (1899). Memoria presentada al Congreso Nacional de 1899 por el Ministro de Justicia, Culto e Instrucción pública Dr. Osvaldo Magnasco. Tomo II - Texto. Buenos Aires: Taller Tipográfico de la Penitenciaría Nacional.

MJCIP (1900). Memoria presentada al Congreso Nacional de 1900 por el Ministro de Justicia, Culto e Instrucción pública. Tomo II - Anexos de Instrucción Pública. Buenos Aires: Taller Tipográfico de la Penitenciaría Nacional.

MJCIP (1903). Memoria presentada al Congreso Nacional de 103 por el Ministro de Justicia, Culto e Instrucción pública Dr. Juan R. Fernández. Tomo III - Anexos de Instrucción 
El destructor de huacas. La acción de Manuel B. Zavaleta en la constitución del "patrimonio arqueológico” calchaquí...

Pública. Buenos Aires: Taller Tipográfico de la Penitenciaría Nacional.

MJCIP (1906). Memoria presentada al Congreso Nacional de 1906 por el Ministro de Justicia, Culto e Instrucción pública. Tomo II - Anexos de Instrucción Pública 1904 y 1905. Buenos Aires: Talleres Gráficos de la Penitenciaría Nacional.

Moreno, F. (1885). Carta a Ramón Toledo, 10 febrero de 1885. Archivo General de la Nación, Sala VII, Catálogo Museo Histórico Nacional, Pieza 3399. Ciudad Autónoma de Buenos Aires.

Moreno, F. (1887). Carta a Manuel Gonnet, 23 de noviembre de 1887. En Farro, M. (2008). Historia de las colecciones en el Museo de La Plata, 1884-1906: naturalistas viajeros, coleccionistas y comerciantes de objetos e historia natural a fines del Siglo XIX (Tesis doctoral). Facultad de Ciencias Naturales y Museo, Universidad de La Plata. Argentina.

Nota de traspaso de la colección arqueológica del Museo de Ciencias Naturales al Museo Etnográfico Archivo Fotográfico y Documental del Museo Etnográfico Juan Bautista Ambrosetti, Fondo de Gestión Institucional AcadémicoAdministrativa Institucional, Serie Historia de las Colecciones, Legajo Zavaleta, Carpeta 2. Ciudad Autónoma de Buenos Aires.

Nota del 14 de febrero de 1978. Archivo Fotográfico y Documental del Museo Etnográfico Juan Bautista Ambrosetti, Fondo de Gestión Institucional Académico-Administrativa Institucional, Serie Historia de las Colecciones, Legajo Zavaleta, Carpeta 2. Ciudad Autónoma de Buenos Aires.

Notes of Happenings at the World's fair (1904, August 6). The Saint Louis republic, Chronicling America: Historic American Newspapers, p. 9. Library of Congress. https:// chroniclingamerica.loc.gov/lccn/sn84020274/1904-0806/ed-1/seq-9/

“Noticia sobre arribo de Zavaleta” (1896, septiembre 4). Les Temps, p. 3.

Páez de la Torre, C. (2013, mayo 12) "El adiós de Avellaneda a su tierra”. La Gaceta. https://www.lagaceta.com.ar/ nota/544356/sociedad/adios-avellaneda-tierra.html
Páez de la Torre, C. (2014, septiembre 29). "La nieve paga impuesto". La Gaceta. https://www.lagaceta.com.ar/ nota/609861/sociedad/nieve-paga-impuesto.html

Parezo, N. y Munro, L. (2010). Bridging the Gulf: Mexico, Brazil and Argentina on display at the 1904 Lousiana Purchase Exposition. Studies in Latin American Popular Culture, 28, 25-47.

Pegoraro, A. (2009). Las colecciones del Museo Etnográfico de la Universidad de Buenos Aires: un episodio en la historia del americanismo en la Argentina, 1890-1927 (Tesis doctoral en Antropología Social). Universidad de Buenos Aires, Argentina.

Penhos, M. (2009). Saint Louis 1904. Argentina en escena. En Di Liscia M. y Lluch, A. (Eds.). Argentina en exposición. Ferias y exhibiciones durante los siglos XIX y XX (pp. 59-84). Sevilla: Consejo de Investigaciones científicas.

Peña de Bascary, S. (1975, junio 27) "Adán Quiroga y la trascendencia de una colección perdida". La Gaceta, p. 1.

Perazzi, P. (2011). La antropología en escena: redes de influencia, sociabilidad y prestigio en los orígenes del Museo Etnográfico de la Universidad de Buenos Aires. Anthropologica, 29, 215-231.

Petitjean, Henri (1897, janvier 22) "La Collection Zavaleta”. Le Figaro, p. 3.

Plenty of material now in St. Louis for great Museum of natural history (1904, october 30). The Saint Louis Republic. Chronicling America: Historic American Newspapers, Part II, p. 6. Library of Congress. https://chroniclingamerica. loc.gov/lccn/sn84020274/1904-10-30/ed-1/seq-18/

Podgorny, I. (1995). De razón a facultad: ideas acerca de las funciones del Museo de La Plata en el periodo 18901918. Runa, 22, 89-104.

Podgorny, I. y Lopes, M. M. (2008). El desierto en una vitrina: Museos e historia natural en la Argentina, 1810-1890. México: Limusa.

Posse, F. (1887). Carta al director del Museo Nacional con copia legalizada de los 275 objetos de la colección. Archivo Fotográfico y Documental del Museo Etnográfico Juan Bautista Ambrosetti, Fondo de Gestión Institucional Académico-Administrativa Institucional, Serie Historia 
de las Colecciones, Legajo Zavaleta, Carpeta 3, F1. Ciudad Autónoma de Buenos Aires.

Pringles (1876a). Estudios antropológicos comenzados en Salta. Anales de la SCA, II, 218-221.

Pringles (1876b). Estudios sobre los calchaquíes. Anales de la SCA, II, 331-334.

Quiroga, A. (1896). Antigüedades calchaquíes. La colección Zavaleta. Boletín del IGA, XVII, 177-210.

Registro Nacional de la República Argentina (1900). $1^{\circ}$ y $2^{\circ}$ Cuatrimestre. Buenos Aires: Taller Tipográfico de la Penitenciaría Nacional.

Rivas, A. I. (2000). Problemas de tenencia de la tierra en los valles del borde andino: el caso del valle de Tafí. Breves contribuciones del IEG, 12. https://ecaths1.s3.amazonaws. com/problematicaterritorialrural/1026860810

Scars on Skulls interest scientist (1904, agosto 21). The Saint Louis Republic. Part II, 14. En Chronicling America: Historic American Newspapers. Library of Congress. https:// chroniclingamerica.loc.gov/lccn/sn84020274/1904-0821/ed-1/seq-14/

Scattolin, M. C. (2003). Los ancestros de Calchaquí: una visión de la Colección Zavaleta. Cuadernos FHCyS, UNJU, 20, 51-79.

Sociedad Científica Argentina [SCA] (1876). Anales de la Sociedad Cientifica Argentina. Tomo II (pp. 15-132).

Sociedad Científica Argentina [SCA] (1876). Segunda Exposición Anual de la Sociedad Científica Argentina. Abierta el 28 de julio y cerrada el 6 de agosto de 1876 . Anales de la Sociedad Cientifica Argentina. Tomo III (pp. 126-150).

Société des Américanistes de Paris [SAP] (1897) "ProcésVerbaux des Séances X. Séance Du mardi 1er. Décembre 1869". Journal de la Société des Américanistes de Paris, VI, 205-207.

Thamm, A. y Castellanos, W. (1902). Registro Gráfico de las Propiedades Rurales del Territorio de La Pampa Central y parte de las provincias limitrofes. http://norbertomollo. blogspot.com/2012/11/mapas-y-planos-antiguos-de-lapampa.html
Tarragó, M. (2003). La arqueología de los Valles Calchaquíes en perspectiva histórica. Anales, Nueva Época, 6, $13-42$.

Tolosa, S. (2014). Ciencia, mercado y desigualdad. Apuntes sobre el intercambio de material arqueológico calchaquí, fin de siglo XIX, principios del XX. Nuevo mundo, mundos nuevos. DOI: 10.4000/nuevomundo.67137

Tolosa, S. (2018). Los Antiguos y el estado. Historia de la construcción material del patrimonio arqueológico, sur de los valles Calchaquies (1877-2008) (Tesis doctoral en Antropología Social). Facultad de Filosofía y Letras, Universidad de Buenos Aires. Argentina.

Tolosa, S. (en prensa). Científicos vs. Huaqueros. Responsabilidad y participación en la competencia comercial de piezas arqueológicas calchaquíes a fines del siglo XIX. Revista Española de Antropología Americana, Universidad Complutense de Madrid.

Zavaleta, M. (1885a). Carta a Ameghino, 28 de enero de 1885. En Torcelli, A. (1914). Obras completas y Correspondencia Cientifica de Florentino Ameghino. Tomo XX, Carta 326 (p. 309). La Plata: Taller de Impresiones Oficiales.

Zavaleta, M. (1885b). Pedido de exoneración de impuestos a la Sala de Representantes (Documento incompleto). Archivo Histórico de Tucumán, Sección Administrativa, Libro 165, año 1885, Folio 273, San Miguel de Tucumán, Argentina.

Zavaleta, M. (1885c). Carta a Julio A. Roca. Archivo General de la Nación, Sala VII, Fondo Julio A. Roca, Correspondencia Recibida, Legajo 1271. Ciudad Autónoma de Buenos Aires.

Zavaleta, M. (1888a). Carta a Ameghino, 10 de agosto de 1888. En Torcelli, A. (1914). Obras completas y Correspondencia Cientifica de Florentino Ameghino. Tomo XX, Carta 578 (p. 507). La Plata: Taller de Impresiones Oficiales.

Zavaleta, M. (1888b). Carta a Ameghino, 14 de noviembre de 1888. En Torcelli, A. (1914). Obras completas y Correspondencia Cientifica de Florentino Ameghino. Tomo XX, Carta 541 (pp. 476-477). La Plata: Taller de Impresiones Oficiales.

Zavaleta, M. (1889). Carta a Ameghino, 30 de septiembre de 1889. En Torcelli, A. (1914). Obras completas y Correspon- 
El destructor de huacas. La acción de Manuel B. Zavaleta en la constitución del "patrimonio arqueológico" calchaquí...

dencia Cientifica de Florentino Ameghino. Tomo XX Carta 599 (p. 523). La Plata: Taller de Impresiones Oficiales.

Zavaleta, M. B. (1906). Catálogo de la Colección Calchaquí de Arqueología y Antropología de Manuel B. Zavaleta. Buenos Aires: Imprenta y Librería Petenello.
Zusman, P. (2012).Panamericanismo e imperialismo no formal: Argentina y las Exposiciones Internacionales de Búfalo (1901) y San Francisco (1915). Scripta Nova, Revista Electrónica de Geografía y Ciencias Sociales. Vol. XVI, 418(64). http://www.ub.es/geocrit/sn/sn-418/sn418-64.htm

(c) (1) Este es un artículo de acceso abierto bajo licencia Creative Commons Reconocimiento 4.0 Internacional 